OPEN ACCESS

Edited by:

Björn Kristian Klatt,

Lund University, Sweden

Reviewed by:

Sydney Moyo,

Rhodes College, United States

Breeanne Jackson

University of California, Merced,

United States

*Correspondence:

Carmen Kowarik

carmen.kowarik@eawag.ch

Specialty section:

This article was submitted to Biogeography and Macroecology,

a section of the journal

Frontiers in Ecology and Evolution

Received: 10 May 2021

Accepted: 15 June 2021

Published: 08 July 2021

Citation:

Kowarik C, Martin-Creuzburg D and Robinson CT (2021)

Cross-Ecosystem Linkages: Transfer of Polyunsaturated Fatty Acids From

Streams to Riparian Spiders via Emergent Insects.

Front. Ecol. Evol. 9:707570. doi: $10.3389 /$ fevo.2021.707570

\section{Cross-Ecosystem Linkages: Transfer of Polyunsaturated Fatty Acids From Streams to Riparian Spiders via Emergent Insects}

\author{
Carmen Kowarik ${ }^{1,2 *}$, Dominik Martin-Creuzburg ${ }^{3}$ and Christopher T. Robinson ${ }^{1,2}$ \\ ${ }^{1}$ Eawag, Department of Aquatic Ecology, Dübendorf, Switzerland, ${ }^{2}$ Institute of Integrative Biology, ETH Zurich, Zurich, \\ Switzerland, ${ }^{3}$ Limnological Institute, University of Konstanz, Konstanz, Germany
}

Polyunsaturated fatty acids (PUFAs) are essential resources unequally distributed throughout landscapes. Certain PUFAs, such as eicosapentaenoic acid (EPA), are common in aquatic but scarce in terrestrial ecosystems. In environments with low PUFA availability, meeting nutritional needs requires either adaptations in metabolism to PUFApoor resources or selective foraging for PUFA-rich resources. Amphibiotic organisms that emerge from aquatic ecosystems represent important resources that can be exploited by predators in adjacent terrestrial habitats. Here, we traced PUFA transfer from streams to terrestrial ecosystems, considering benthic algae as the initial PUFA source, through emergent aquatic insects to riparian spiders. We combined carbon stable isotope and fatty acid analyses to follow food web linkages across the ecosystem boundary and investigated the influence of spider lifestyle (web building vs. ground dwelling), season, and ecosystem degradation on PUFA relations. Our data revealed that riparian spiders consumed considerable amounts of aquatic-derived resources. EPA represented on average $15 \%$ of the total fatty acids in riparian spiders. Season had a strong influence on spider PUFA profiles, with highest EPA contents in spring. Isotope data revealed that web-building spiders contain more aquatic-derived carbon than ground dwelling spiders in spring, although both spider types had similarly high EPA levels. Comparing a natural with an anthropogenically degraded fluvial system revealed higher stearidonic acid (SDA) contents and $\Sigma \omega 3 / \Sigma \omega 6$ ratios in spiders collected along the more natural river in spring but no difference in spider EPA content between systems. PUFA profiles of riparian spiders where distinct from other terrestrial organism and more closely resembled that of emergent aquatic insects (higher $\Sigma \omega 3 / \Sigma \omega 6$ ratio). We show here that the extent to which riparian spiders draw on aquatic PUFA subsidies can vary seasonally and depends on the spider's lifestyle, highlighting the complexity of aquatic-terrestrial linkages.

Keywords: ecosystem degradation, emergent insects, fluvial systems, food web, PUFA - polyunsaturated fatty acids, resource subsidies, riparian spiders, stable isotope C 13 


\section{INTRODUCTION}

Aquatic and terrestrial ecosystems are open units that are connected in a tangled web via various resource fluxes oriented in both directions (Baxter et al., 2005). This cross-boundary transfer of resources (allochthonous resource subsidies) is essential towards sustaining both ecosystems. Some relevant examples of resource transfer from aquatic to terrestrial systems are fish predation by riparian predators (or humans), amphibiotic organisms leaving the water during their life cycle, and water birds feeding on aquatic plants (Richardson et al., 2010; Gladyshev et al., 2013). Riparian communities often rely on aquatic-derived subsidies with whole populations at times being fueled by aquatic resources, most notably in resource poor environments (Anderson and Polis, 1998; Sabo and Power, 2002). Emergent aquatic insects play a crucial role in adjacent riparian food webs, as they serve as prey for various predators, such as birds, bats, lizards (Sabo and Power, 2002; Iwata et al., 2003; Lam et al., 2013) spiders or beetles (Paetzold et al., 2005). The abundance of spiders, for instance, has been shown to correlate strongly with the amount of emergent aquatic insects (Kato et al., 2003, 2004; Paetzold et al., 2005, 2008, 2011; Iwata, 2007; Burdon and Harding, 2008) and stable isotope analysis revealed that some riparian spiders obtain up to $100 \%$ of their carbon from aquaticderived organic matter (Sanzone et al., 2003). Stable isotope analysis has been used successfully to disentangle food webs and differentiate between allochthonous and autochthonous carbon sources in consumer tissues (DeNiro and Epstein, 1978), although its use is dependent on the degree of isotopic discrimination between basal resources (Collier et al., 2002). Aquatic-derived organic material is generally more depleted in $\delta^{13} \mathrm{C}$ than terrestrial organic material (Rounick and Winterbourn, 1986) and this difference can be used to estimate dietary contributions. More recently compound-specific stable isotope analysis (CSIA) has been suggested as an additional method to trace energy flows through food webs (Twining et al., 2020b).

The strong effect of aquatic subsidies on riparian communities cannot be explained solely by quantity of carbon transfer, as biomass fluxes from aquatic to terrestrial ecosystems are often lower than fluxes in the opposite direction (Bartels et al., 2012). Possible explanations are still poorly understood. One aspect to consider are differences in insect phenology between aquatic and terrestrial ecosystems. Aquatic insects typically emerge earlier in the year than terrestrial insects thus representing an important dietary supplement for riparian predators when the amount of terrestrial food sources in spring is still low (Nakano and Murakami, 2001). In addition, aquatic subsidies are thought to be of higher nutritional quality and energy density than terrestrial subsidies (Moyo et al., 2017).

One important determinant of nutritional quality is the content of polyunsaturated fatty acids (PUFAs), especially the content of $\omega-3$ PUFAs, which is typically much higher in aquatic than in terrestrial resources (Hixson et al., 2015). It is generally assumed that the C18 PUFAs linoleic acid (LIN,

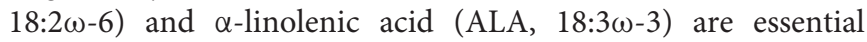
for all animals and thus have to be taken up with food, albeit the ability of some insects to synthesize LIN has been documented (Blomquist et al., 1991). Dietary uptake of the physiologically important long-chain (LC, $\geq$ C20) PUFAs, such as eicosapentaenoic acid (EPA, 20:5 $\omega-3$ ), is also important. Even though many animals are able to elongate and desaturate dietary C18 precursors to LC-PUFAs, this internal bioconversion pathways is often inefficient and energy consuming and thus incapable of covering LC-PUFA demands (Pawlosky et al., 1997; Brenna et al., 2009; Castro et al., 2012). In this context, it is generally assumed that consumers largely reflect the PUFA profile of their food (Iverson et al., 2004; Brett et al., 2006; Torres-Ruiz et al., 2010). LC-PUFAs are important because of their central role in membrane physiology and as precursors for signaling molecules acting on reproduction and the immune system (Stillwell and Wassall, 2003; Stanley, 2014; Schlotz et al., 2016). Better growth and development on naturally LC-PUFArich diets and diets that were supplemented with LC-PUFAs has been documented for different species (Müller-Navarra et al., 2000; Martin-Creuzburg et al., 2010; Twining et al., 2016b).

The fundamental dichotomy in the occurrence of PUFAs in aquatic and terrestrial ecosystems, with aquatic systems being generally richer in $\omega-3$ PUFAs, especially long chain ones, derives from differences in PUFA profiles of the respective primary producers (Hixson et al., 2015). Several algal groups produce high amounts of LC-PUFAs, such as EPA, whereas most terrestrial plants, except for some bryophytes, lack the ability to synthesize PUFAs with more than C18 atoms (Harwood, 1996; Sayanova and Napier, 2004; Uttaro, 2006; Hixson et al., 2015). In fact, aquatic ecosystems have been suggested to be the principal source of LC-PUFAs and a net transfer from aquatic to terrestrial systems has been recognized (Moyo et al., 2017). Emergent aquatic insects represent an important vector for LC-PUFA transfer across the ecosystem boundary to terrestrial consumers (Gladyshev et al., 2013; Martin-Creuzburg et al., 2017; Popova et al., 2017; Fritz et al., 2019) and some riparian predators might have specialized on exploiting this high-quality prey. Indeed, low dietary LC-PUFA provision can cause impaired development or lower breeding success of certain species (e.g., tree swallows), even with an abundance of other food sources (Twining et al., 2016a, 2018). PUFA availability might also be the reason why, e.g., riparian lizards without access to aquatic insects show reduced growth rates (Sabo and Power, 2002). Low amounts of aquatic-derived subsidies (i.e., low LCPUFA input) are also linked with reduced immune function in riparian spiders (Fritz et al., 2017). Human impacts on river morphology (e.g., channelization, construction of barriers) or water quality (e.g., pollution, nutrient levels) can alter crossecosystem nutrient fluxes, potentially resulting in resource mismatches and a decoupling of aquatic and terrestrial systems (Laeser et al., 2005; Paetzold et al., 2011; Larsen et al., 2016; Muehlbauer et al., 2020).

Here, we examined the content of five physiologically

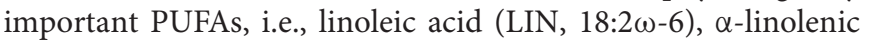

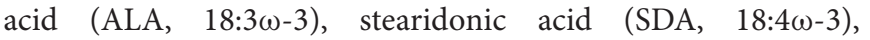
arachidonic acid (ARA, 20:4 $\omega-6$ ), and eicosapentaenoic acid (EPA, 20:5 $\omega-3)$ in riparian spiders along two rivers with different degrees of anthropogenic disturbance (Figure 1). In addition, we checked samples for the physiologically important 


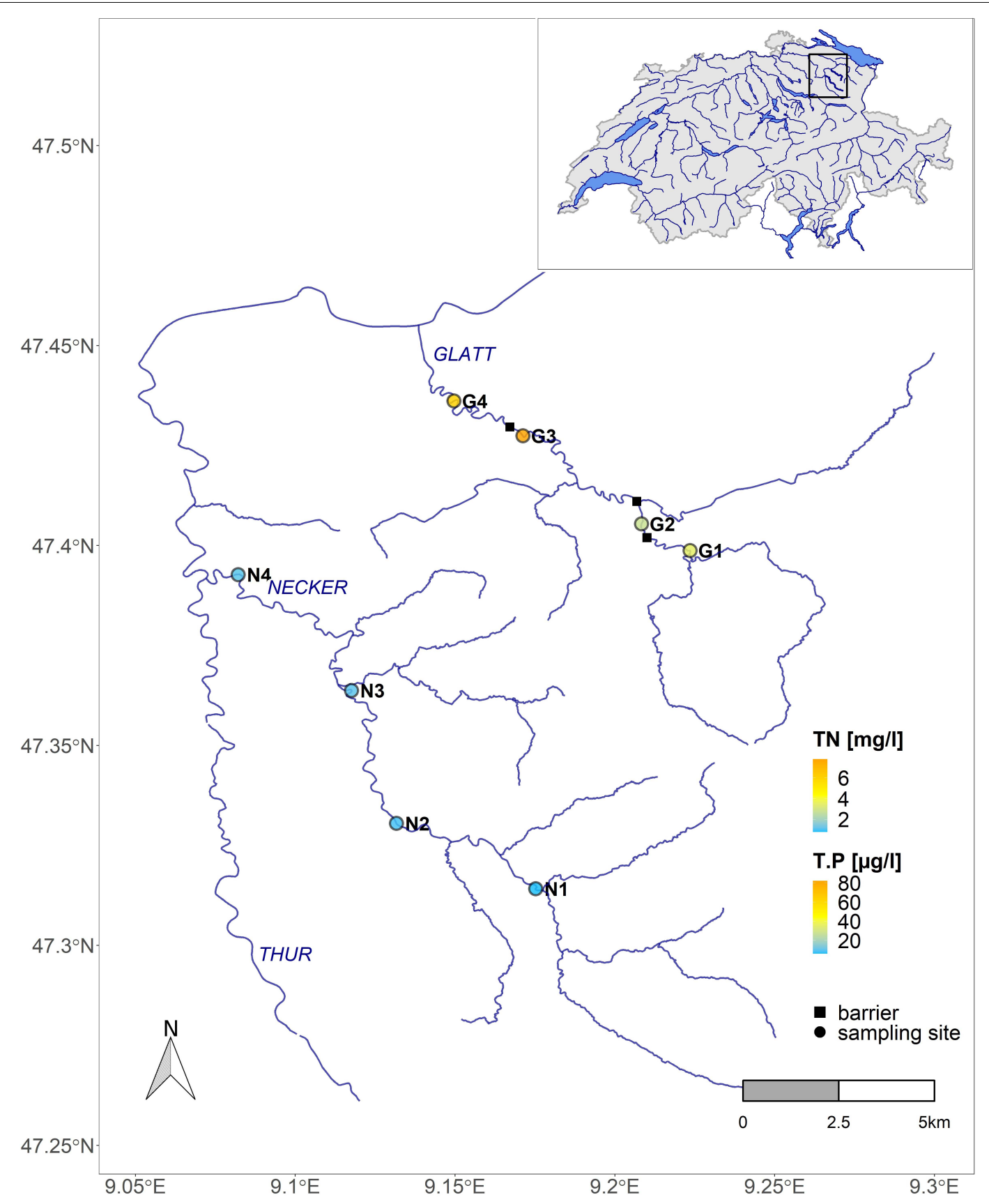

FIGURE 1 | Map of sampling sites on the Necker (N) and Glatt (G) in the Thur catchment, northeast Switzerland (map insert at top right). The color gradient represents nutrient levels (T.P, total Phosphorus; TN, total Nitrogen). Circles represent sampling sites; squares represent major barriers blocking bed movement.

docosahexaenoic acid (DHA, 22:5 $\omega$-3), although DHA levels are normally lower in freshwater than in marine systems (Twining et al., 2020a). Two types of riparian spiders were analyzed at different times of the year: ground-dwelling spiders roaming the riparian area for prey and web-building spiders that are relatively stationary in prey capture. We explored potential differences in individual PUFA content between spider types and to what extent the different spider types reflected the PUFA profiles of aquatic emergent insects. We used site-specific differences in
PUFA provision to track PUFA transfer from periphyton via emergent aquatic insects to riparian spiders.

Our main hypotheses included: (1) riparian spiders are rich in EPA and their $\Sigma \omega 3 / \Sigma \omega 6$ ratio is comparable to aquatic organisms because they feed on emergent aquatic insects; (2) aquatic-derived PUFA content of spiders is highest in spring when aquatic emergent insects are most abundant; (3) emergent aquatic insect consumption depends on spider type (webbuilding vs. ground-dwelling), because the two groups have 
access to different prey types (e.g., ground vs aerial prey) resulting in differences in PUFA content between them; and (4) riparian spiders living along anthropologically disturbed systems ingest low amounts of aquatic material and contain less aquatic-derived PUFAs because human impacts can alter cross ecosystem linkages such that spiders cannot draw on aquatic resources. To test our hypotheses, we used a combination of fatty acid, carbon stable isotope and CSIA analyses. To our knowledge, this is one of the first studies showing a tight link between PUFA profiles of riparian spiders and emergent aquatic insects.

\section{MATERIALS AND METHODS}

\section{Site Description}

Sampling was conducted at eight sites along two streams in the Thur River catchment in northeast Switzerland (Figure 1). Both streams (Necker, Glatt) are sixth-order pre-alpine streams with a flow regime including regular natural flood events. The Necker is a non-regulated system with low nutrient levels and a natural flow-sediment regime. It drains a basin of ca. $126 \mathrm{~km}^{2}$ with elevation ranging from 1550 to $550 \mathrm{~m}$ a.s.l. and has a longterm mean annual discharge of $3.3 \mathrm{~m}^{3} / \mathrm{s}$ (hydrograph station Achsäge). Sampling sites $(n=4)$ ranged in elevation from ca. 700 (upper most site) to $550 \mathrm{~m}$ a.s.l. (lower most site). The Glatt is a heavily regulated system with many channel alterations realized over the years, including numerous barriers impeding sediment movement and changing river morphology. In addition, nutrient levels are higher (TN: $4-8 \mathrm{mg} / \mathrm{l}$, T-P: $30-70 \mu \mathrm{g} / \mathrm{l}$ ) than in the Necker, due to the strong agricultural land use. The Glatt drains a basin of ca. $90 \mathrm{~km}^{2}$ with elevation ranging between 950 and $480 \mathrm{~m}$ a.s.l. Long-term mean annual discharge is $2.7 \mathrm{~m}^{3} / \mathrm{s}$ at the hydrograph station Oberbüren. Here, sampling sites $(n=4)$ ranged in elevation between 620 to $500 \mathrm{~m}$ a.s.l.

\section{Field Sampling}

Samples were taken between April and October 2019. Water samples, periphyton, emergent aquatic insects, and spiders were collected in spring (April/May), summer (June/July/August) and autumn (September/October) to assess seasonal differences. No sampling was conducted during winter as most spiders are not active during the winter month, because they are either hibernating in the soil or die in autumn and the next generation hatches from resting eggs in spring. Benthic algae (as periphyton) were taken to quantify resource availability at each site and season. Three stones were randomly selected from the riverbed and returned to the laboratory. The biofilm on each stone was detached with a metal brush and an aliquot of the periphyton suspension was filtered through a glass fiber filter (Whatman $\mathrm{GF} / \mathrm{F}$ ). This procedure was done twice (2 aliquots), one filter was used for fatty acid extraction (frozen at $-20^{\circ} \mathrm{C}$ until analysis) and the other for determination of ash free dry mass (AFDM). For AFDM estimation, filters were dried at $60^{\circ} \mathrm{C}$, weighed, combusted for $3 \mathrm{~h}$ at $500^{\circ} \mathrm{C}$, and then reweighed.

Emergent aquatic insects were captured alive using floating emergence traps with a base area of $0.25 \mathrm{~m}^{2}$ and mesh size of $100 \mu \mathrm{m}$. Three emergence traps were deployed at each site.
Sampling started in early April with emergence traps deployed weekly (2-3 days/week) until mid-May and then monthly (2x 2-3 days/month) from June to October. Adult aquatic insects were collected from emergence traps after 2-3 days on each deployment. Samples were returned to the laboratory, frozen, and then counted and identified to the lowest practicable taxonomic level. Samples were stored short-term (a few weeks) at $-20^{\circ} \mathrm{C}$ and longer (month) at $-80^{\circ} \mathrm{C}$ when necessary. Trichoptera were not considered in this study because of too few samples for adequate assessment. As reference material, terrestrial insects were collected once per season using a sweep net, returned to the laboratory and frozen as described above until further analysis.

Riparian spiders were collected within $0-2 \mathrm{~m}$ distance from the shoreline once per season at each site. We collected spiders from two different functional feeding guilds (Wise, 1993; Nyffeler et al., 1994; Sanzone et al., 2003); i.e., ground-dwelling spiders hunting for their prey on the ground (ground spiders) and spiders that use orb-webs for prey capture (web spiders). All ground spiders belonged to the family Lycosidae (genera Pardosa or Pirata/Piratula) and all web spiders belonged to the family Tetragnathidae (genus: Tetragnatha). Spiders in both groups were collected using a mouth aspirator. In addition, spiders were sampled at different distances from the stream at the Necker (site N4) in June 2020 to assess potential changes in PUFA content with distance from the river. Here, at least three individuals of each group were collected at 0-2 $\mathrm{m}, 5-10 \mathrm{~m}, 20-30 \mathrm{~m}, 40-$ $50 \mathrm{~m}$ distance from the stream shore. All collected spiders were returned to the laboratory, kept in containers over night to allow gut clearance, and then frozen for later analysis.

\section{Laboratory Procedures}

\section{Fatty Acid Analysis}

We analyzed fatty acids of 72 periphyton samples, 233 emergent insect samples (85 Diptera, 75 Ephemeroptera, 73 Plecoptera), 140 spiders (69 web spiders, 71 ground spiders, in addition 24 spider samples for distance gradient) and, as reference, 9 terrestrial insect samples (Diptera). The PUFAs analyzed included LIN, ALA, SDA, ARA, and EPA. Prior to fatty acid extraction, samples were freeze-dried, and the dry mass was determined with an ultrafine balance. Weighed samples were extracted in dichloromethane/methanol (2:1 v/v) over night and an internal standard (17:0 ME and 23:0 ME) was added for analysis. After $5 \mathrm{~min}$ in an ultrasound bath, particles were separated by centrifugation $(3500 \mathrm{~g}, 5 \mathrm{~min})$. The supernatant of each sample was evaporated to dryness under nitrogen, resuspended in $4 \mathrm{ml}$ methanolic $\mathrm{HCl}$ for transesterification, and then incubated at $60^{\circ} \mathrm{C}$ for $20 \mathrm{~min}$ to obtain fatty acid methyl esters (FAMEs). After cooling, hexane was added, and each sample was mixed and the upper phase consisting of hexane was transferred to a new vial. This procedure was repeated two more times, the hexane fractions pooled, and the composite sample evaporated to dryness under nitrogen. Each sample was resuspended in 20 to $200 \mu$ l of hexane, depending on initial sample dry mass, and analyzed for FAME content using gas chromatography (7890B gas chromatograph, Agilent Technologies, Waldbronn, Germany); configuration 
details (Martin-Creuzburg et al., 2010). fatty acids were identified based on their retention time and their mass spectra, and quantified by comparison to internal standards using multipoint calibration curves of known concentration (for details see Martin-Creuzburg et al., 2017).

\section{Stable Isotope Analysis}

We used the carbon stable isotope ratio $\left(\delta^{13} \mathrm{C}\right)$ to estimate the contribution of aquatic-derived material to riparian spiders and to compare with the results from fatty acid analysis. Samples from both spider groups, emergent aquatic insects from each site and season, and terrestrial insects were used for carbon stable isotope analysis (sampled as described above). For each sample, 0.7-0.9 $\mathrm{mg}$ of freeze-dried ground material was weighed and placed into tin capsules. Individual samples were combusted in a Vario PYRO Cube elemental Analyzer (Elementar Analysensysteme GmbH, Langenselblod, Germany) connected to an IsoPrime isotope ratio mass spectrometer (GV instruments Ltd., Manchester, United Kingdom) to measure total C content and $\delta^{13} \mathrm{C}$. The $\delta^{13} \mathrm{C}$ values are presented in permille $(\% 0)$ after normalization to reference material (NBS 19, L-SVEC, IAEAN-1 and IAEA-N-2, provided by Biogeochemical Laboratories, Indiana University). Analytical uncertainty was $0.1 \%$ for $\delta^{13} \mathrm{C}$.

\section{Compound-Specific Stable Isotope Analysis}

To validate the aquatic origin of LC-PUFAs, we analyzed 12 fatty acid extracts using CSIA. Carbon isotope ratios of combined C18 fatty acids and combined C20 fatty acids were analyzed using a GC-IRMS (Thermo Scientific; Trace Gas 1310 with a DB5MS column connected with GC Isolink to IR-MS: Delta V Advantage). Peak separation on this column was sufficient to differentiate between C18 und C20 fatty acids but did not allow to differentiate between single fatty acids. We used the following equation to account for differences in isotope signals due to addition of a methyl group during the conversion from fatty acids to FAME:

$$
\delta^{13} C_{F A}=\frac{(n+1) \times \delta^{13} C_{F A M E}-\delta^{13} C_{M e H C l}}{n}
$$

where, $n$ represents the number of $\mathrm{C}$ atoms in the fatty acids, $\delta^{13} C_{F A M E}$ isotope ratio of fatty acid methyl esters and $\delta^{13} C_{M e H C l}$ isotope ratio of $\mathrm{MeHCl}$ used for the derivatization. All samples were measured twice, and the average used for validation. The $\delta^{13} \mathrm{C}$ of $\mathrm{MeHCl}$ was $-23.01 \%$.

\section{Data Analysis}

\section{PUFA Content in Riparian Spiders and Transfer Across Trophic Levels}

All analyses were conducted in R 3.6.2 (R Core Team, 2019). Five individual PUFAs (LIN, ALA, SDA, ARA, and EPA) were examined (DHA was detectable in trace amounts only in a few samples and therefore excluded from the analyses). We investigated individual PUFA content of three trophic levels, i.e., periphyton, emergent aquatic insects and riparian spiders. Individual PUFA content was calculated on a relative basis (\% of total FA).
Spider individual PUFA content and $\Sigma \omega 3 / \Sigma \omega 6$ ratio was compared among spider types, seasons and the two fluvial systems using a factorial ANOVA (type III) (factors = season, spider type, river) (Anova, package "car"; Fox and Weisberg, 2019). Main and interaction effects were calculated for all three levels. When interaction effects were significant $(p<0.05)$, post hoc tests were run separately for each pair of combinations. When interactions were not significant $(p>0.05)$, significant main effects $(P<0.05)$ were tested. In both cases, multiple pairwise post hoc comparisons of estimated marginal means (EMMs) with tukey correction (package "emmeans"; Lenth, 2021) were conducted. Data were tested for normality and homogeneity of variance assumptions and transformed where required. Percent data were transformed using the arcsine square root transformation (Sokal and Rohlf, 1995). The values reported represent untransformed means.

We used the difference in PUFA provision (PUFA content in emerging aquatic insects and periphyton) between sites and seasons (see Supplementary Material) to explore the transfer of PUFAs across trophic levels. If the same differences occur at all levels, transfer is likely. We calculated average individual PUFA content for periphyton, each of the emergent insect orders, and the two spider types per site and season (as measurement were not paired within site); the values were arcsine square root transformed. We used average values to investigate if there is a positive relationship among trophic levels in regard to individual PUFAs. We used a linear mixed effects model (lmer package "lme4"; Bates et al., 2015) with individual PUFA content of the lower trophic level as the predictor variable. We included season and river as a random effect to account for the two different systems and multiple sampling at the same sites. The first step was from periphyton to emergent insects, the second from emergent insects to spiders. Conditional $R^{2}$ (variance explained by complete model; $R^{2} c$ ) and marginal $R^{2}$ (variance explained by fixed effects; $R^{2} \mathrm{~m}$ ) were calculated (package "MuMIn"; Barton, 2020) to estimate the variance explained by fixed effects (Nakagawa and Schielzeth, 2013). If variance explained was $<0.1$, predictive effect was not considered to be ecologically significant. If $R^{2} \mathrm{~m}$ was $<0.3$ it was considered as a weak effect, for $R^{2} \mathrm{~m}<0.5$ as a moderate effect and for $R^{2} \mathrm{~m}>0.5$ as a strong effect (Nakagawa and Cuthill, 2007). A significant predictive effect of individual PUFAs of the lower trophic level for the higher trophic level is an indicator of transfer of the respective PUFA.

\section{Multivariate Analysis of Similarity}

We used the five selected PUFAs for non-metric multidimensional scaling (nMDS) to ordinate PUFA composition among predator and prey in two dimensions using rank-order dissimilarities. All values were arcsine squareroot transformed before ordination. Multivariate outliers were removed by the minimum volume ellipsoid-based robust distance (R package "mvoutlier" Filzmoser and Gschwandtner, 2018). To assess similarities in PUFA composition between spider types, and among predators and their food sources, we used analysis of similarity (ANOSIM, R package "vegan"; Oksanen et al., 2019) with 999 permutations. We used the ANOSIM global $R$-value of the pairwise comparisons as an 
indicator of similarity. The value can range between -1 to 1 , with global $R$-value close to 1 indicating the sample pairs being different, while values close to 0 indicate that the pair is similar. In greater detail, a global $R$-value of $<0.25$ indicates that groups are hardly separated, $R<0.5$ shows that groups differ but with some overlap, and $R>0.75$ implies groups are well separated (Jaschinski et al., 2011). Negative values can occur and indicate greater dissimilarity within a group than among groups (Chapman and Underwood, 1999).

\section{Food Source Reconstruction}

The $\delta^{13} \mathrm{C}$ of riparian spiders were compared in a similar fashion as described above (factorial ANOVA) to see if spider type, season, and system influenced carbon isotope ratios. We used a two-source mixing model (aquatic/terrestrial insect) to calculate the proportion of carbon obtained from aquatic sources $\left(\mathrm{P}_{a q}\right)$ in spider tissue. Carbon isotope ratios of aquatic and terrestrial insects were compared to see if food sources can be discriminated from each other. Average $\delta^{13} \mathrm{C}$ was calculated per river and season for both prey and predator groups. When food sources where distinct, the proportion of aquatic diet was calculated using the equation (modified from DeNiro and Epstein, 1978; Sanzone et al., 2003):

$$
P_{a q}=\frac{\delta^{13} C_{p r e d}-\delta^{13} C_{t e r}-T E F}{\delta^{13} C_{a q}-\delta^{13} C_{t e r}}
$$

where; $\delta^{13} \mathrm{C}_{\text {pred }}=$ natural abundance of $\delta^{13} \mathrm{C}$ of riparian spiders, $\delta^{13} \mathrm{C}_{t e r}=$ natural abundance of $\delta^{13} \mathrm{C}$ of terrestrial insect reference samples, and $\delta^{13} \mathrm{C}_{a q}=$ natural abundance of $\delta^{13} \mathrm{C}$ of emergent aquatic insects. TEF is the average trophic enrichment factor between predator and prey (approximately $1.1 \%$ ), similar to DeNiro and Epstein (1978), and similar to experimentally determined values for lycosid spiders (Oelbermann and Scheu, 2002).

We then included PUFA profiles in the food source reconstruction, as a combination of PUFA and carbon isotope data can provide more detailed information about the use of different prey groups by spiders at the different sites and seasons. Likely food sources were investigated using a Bayesian model (package "MixSiar"; Stock et al., 2018) combining the information about the diet from all measured parameters $\left(\delta^{13} \mathrm{C}\right.$ and 5 PUFAs). For $\delta^{13} \mathrm{C}$, we used the same TEF as described above (approximately 1.1\%0, (DeNiro and Epstein, 1978). Metabolic effects are an important topic for PUFAs when trying to estimate food sources. Although it is generally assumed that predators largely reflect the PUFA signature of their prey, metabolic effects should be taken into account (Galloway and Budge, 2020). We used two approaches to verify that LC-PUFAs we found in riparian spiders derived from aquatic food sources, or if spiders were able to elongate shorter chain PUFAs into LC-PUFAs (some recent studies suggest that more species than previously thought are able to do this conversion or that LC-PUFAs might be produced in the soil food web (Kabeya et al., 2018; Menzel et al., 2018; Garrido et al., 2019; Kabeya et al., 2020): (1) a distance gradient and (2) an approach using CSIA. For the distance gradient, we used the samples collected from different shoreline distances at Necker site N4 from June 2020 (see above). We compared samples from the different distances using a oneway ANOVA with post hoc pairwise comparisons of estimated marginal means when significant. To capture trends (decrease or increase with distance from shore), we also used a general additive model (GAM, package "mgcv", Wood, 2017). For the second approach, we analyzed carbon isotope ratio for combined C18 fatty acids and combined C20 fatty acids of a small subsample of aquatic insects, terrestrial insects, web spiders and ground spiders (3 per group). Terrestrial insects only contained trace amounts of $\mathrm{C} 20$ fatty acids, so we used the carbon isotope ratio of C18 fatty acids as a baseline. This is a valid approximation, because carbon isotope ratios of $\mathrm{C} 18$ and C20 fatty acids in aquatic insects were very similar to each other (C18: $-39.3 \%$; C20: $-39.6 \%$ ).

We used the information from the distance gradient and CSIA to exclude PUFAs that might have been internally metabolized from the Bayesian model. Due to a lack of feeding experiments, a trophic enrichment of zero was used for the remaining PUFAs. To check if further assumptions of the mixing model were fulfilled, we checked if values of predators (-TEF) lay within range of prey values using NMDS analysis. We used the Bayesian model to find dietary contribution of the different prey groups in the different systems and seasons. Average values per river and season were used for prey groups and the model was run separately for the two spider types with uninformative priors. River was set as a random effect and MCMC chain length was set to 300 000. Gelman-Rubin and Geweke diagnostics were applied to test model convergence.

\section{RESULTS}

\section{PUFA Content in Riparian Spiders}

Polyunsaturated fatty acids comprised on average $39.0 \pm 8.2 \%$ of total fatty acids in web spiders and $41.8 \pm 8.4 \%$ in ground spiders. Riparian spiders were especially rich in $\omega$-3 PUFAs (Table 1). EPA made up the largest proportion with $14.3 \pm 7.0 \%$ of total fatty acids in web spiders and $15.6 \pm 7.4 \%$ in ground spiders (Figure 2 and Table 1). This was slightly lower than EPA content in aquatic insects $(18.8 \pm 6.3 \%)$, but higher than in the measured terrestrial insects $(1.1 \pm 1.2 \%)$. Levels of ALA and SDA were also close to those in emergent aquatic insects (Table 1; for PUFA content in spiders per dry mass see Supplementary Table 1). The ratio of $\Sigma \omega 3 / \Sigma \omega 6$ of riparian spiders was lower than in most emergent aquatic insects $(3.9 \pm 4.6)$, but on average close to 1 (web spiders: 1.34, ground spiders: 0.97 ), while measured terrestrial insects had $\Sigma \omega 3 / \Sigma \omega 6$ ratios of $0.4 \pm 0.2$.

Season, spider type, fluvial system and the interaction of the factors had different effects on individual PUFAs (Table 2). We found the most pronounced seasonal difference in EPA content with highest values in spring in both spider types. An opposite pattern, with significantly highest values in autumn, was visible for LIN content. For the other PUFAs, seasonal patterns were less strong and differed between spider types and fluvial systems (Figure 2 and Table 1). The strongest difference between spider types we found in ARA content, which was significantly higher in ground spiders than in web spiders. In contrast the SDA 
TABLE 1 | Carbon isotope ratios and individual PUFAs (\% of total fatty acids) for the different trophic levels by stream and season (mean \pm standard deviation). N, Necker; G, Glatt.

\begin{tabular}{|c|c|c|c|c|c|c|c|c|c|c|c|c|}
\hline & & season & river & $\begin{array}{c}\delta^{13} \mathrm{C} \\
\text { mean } \pm \text { SD }\end{array}$ & $\begin{array}{c}8^{13} \mathrm{C} \\
\mathrm{n}\end{array}$ & $\begin{array}{c}\text { LIN } \\
\text { mean } \pm \text { SD }\end{array}$ & $\begin{array}{c}\text { ALA } \\
\text { mean } \pm \text { SD }\end{array}$ & $\begin{array}{c}\text { SDA } \\
\text { mean } \pm \text { SD }\end{array}$ & $\begin{array}{c}\text { ARA } \\
\text { mean } \pm \text { SD }\end{array}$ & $\begin{array}{c}\mathrm{EPA} \\
\text { mean } \pm \text { SD }\end{array}$ & $\begin{array}{c}\Sigma \omega 3 / \Sigma \omega 6 \\
\text { mean } \pm \text { SD }\end{array}$ & $\begin{array}{c}\text { fatty acid } \\
n\end{array}$ \\
\hline \multirow{6}{*}{\multicolumn{2}{|c|}{ periphyton }} & spring & G & & & $5 \pm 2.7$ & $5.2 \pm 2.4$ & $2.7 \pm 1.7$ & $0.8 \pm 0.9$ & $13.7 \pm 6$ & $4.8 \pm 2.7$ & 10 \\
\hline & & & $\mathrm{N}$ & & & $8.2 \pm 6.6$ & $4.9 \pm 1.3$ & $10.8 \pm 3.3$ & $0 \pm 0$ & $4.1 \pm 1.1$ & $3.2 \pm 1.3$ & 9 \\
\hline & & summer & G & & & $7.5 \pm 2.9$ & $4 \pm 3.5$ & $0.2 \pm 0.6$ & $0.2 \pm 0.7$ & $2.3 \pm 2.8$ & $0.9 \pm 0.8$ & 12 \\
\hline & & & $\mathrm{N}$ & & & $5.9 \pm 1.3$ & $4.5 \pm 1.1$ & $1.4 \pm 1.5$ & $1 \pm 1.3$ & $3.5 \pm 2$ & $1.4 \pm 0.5$ & 12 \\
\hline & & autumn & G & & & $6 \pm 2.5$ & $4.8 \pm 3.2$ & $1.1 \pm 1.2$ & $1.2 \pm 1.2$ & $3.2 \pm 2$ & $1.3 \pm 0.5$ & 12 \\
\hline & & & $\mathrm{N}$ & & & $12.4 \pm 4.6$ & $3.6 \pm 0.9$ & $1.6 \pm 1.3$ & $0.1 \pm 0.3$ & $2.2 \pm 1.5$ & $0.8 \pm 0.9$ & 12 \\
\hline \multirow{18}{*}{$\begin{array}{l}\text { Emergent aquatic } \\
\text { insect }\end{array}$} & \multirow[t]{6}{*}{ Diptera } & spring & G & $-30.4 \pm 2.4$ & 2 & $13.3 \pm 4.8$ & $6.1 \pm 2.3$ & $2.6 \pm 2.9$ & $0.8 \pm 1.1$ & $22.4 \pm 5.4$ & $2.6 \pm 1.3$ & 17 \\
\hline & & & $\mathrm{N}$ & $-33.8 \pm 1.5$ & 2 & $11.6 \pm 8$ & $6.6 \pm 3.2$ & $5.9 \pm 3.7$ & $0.6 \pm 1$ & $17.4 \pm 6.6$ & $3.6 \pm 2.3$ & 18 \\
\hline & & summer & G & $-29.0 \pm 1.5$ & 9 & $21.5 \pm 5.4$ & $6.4 \pm 4.3$ & $0.9 \pm 1.4$ & $5.5 \pm 1.7$ & $19.3 \pm 7.1$ & $1.1 \pm 0.5$ & 14 \\
\hline & & & $\mathrm{N}$ & $-29.1 \pm 0.6$ & 4 & $17.8 \pm 4.8$ & $7.8 \pm 1.9$ & $0.9 \pm 1.3$ & $4.7 \pm 2.6$ & $23.5 \pm 7.4$ & $1.6 \pm 0.8$ & 11 \\
\hline & & autumn & G & $-29.7 \pm 2.3$ & 7 & $23 \pm 8.6$ & $8.3 \pm 6.4$ & $0.8 \pm 0.8$ & $3.7 \pm 2.1$ & $21.2 \pm 5.6$ & $1.5 \pm 1.2$ & 13 \\
\hline & & & $N$ & $-28.8 \pm 0.4$ & 5 & $22.8 \pm 5.4$ & $7.8 \pm 1.9$ & $1.2 \pm 1.1$ & $3.3 \pm 2$ & $19.2 \pm 8.6$ & $1.2 \pm 0.5$ & 12 \\
\hline & \multirow[t]{6}{*}{ Ephemeroptera } & spring & $G$ & $-33.0 \pm 1.5$ & 4 & $3.5 \pm 1.5$ & $5.3 \pm 2.8$ & $2.9 \pm 1.6$ & $0.8 \pm 1.1$ & $14.5 \pm 5.2$ & $6.5 \pm 3.7$ & 11 \\
\hline & & & N & $-32.6 \pm 0.3$ & 2 & $3.6 \pm 2.7$ & $4.8 \pm 2$ & $6.1 \pm 2.9$ & $1.5 \pm 3.4$ & $13.9 \pm 7.6$ & $8 \pm 4.3$ & 10 \\
\hline & & summer & G & $-33.3 \pm 2.0$ & 7 & $4 \pm 1.3$ & $11.2 \pm 6.7$ & $2.8 \pm 1.3$ & $1.5 \pm 1$ & $17 \pm 5.8$ & $6.6 \pm 3.8$ & 17 \\
\hline & & & $\mathrm{N}$ & $-33.8 \pm 1.5$ & 7 & $3.5 \pm 1.2$ & $8 \pm 3.8$ & $4 \pm 2.5$ & $1.1 \pm 0.6$ & $19.3 \pm 5.7$ & $7.2 \pm 1.9$ & 17 \\
\hline & & autumn & G & $-34.2 \pm 0.5$ & 5 & $3.7 \pm 1.4$ & $11 \pm 5.8$ & $2.1 \pm 0.9$ & $0.9 \pm 0.5$ & $21.5 \pm 6.8$ & $7.8 \pm 2.7$ & 11 \\
\hline & & & $\mathrm{N}$ & $-34.1 \pm 0.7$ & 3 & $13 \pm 32.6$ & $4.8 \pm 3.7$ & $2.9 \pm 1.4$ & $0.6 \pm 0.6$ & $19.8 \pm 9.3$ & $10.6 \pm 5.7$ & 9 \\
\hline & \multirow[t]{6}{*}{ Plecoptera } & spring & $G$ & $-35.5 \pm 1.5$ & 2 & $13.9 \pm 10.8$ & $14.9 \pm 9.7$ & $1.1 \pm 1.5$ & $2.9 \pm 2.5$ & $17.2 \pm 9.7$ & $2.8 \pm 1.9$ & 9 \\
\hline & & & $\mathrm{N}$ & $-31.3 \pm 0.4$ & 4 & $8 \pm 4.1$ & $12.1 \pm 2.4$ & $7.5 \pm 4.4$ & $2 \pm 0.8$ & $18.3 \pm 3.2$ & $4.5 \pm 2$ & 20 \\
\hline & & summer & $G$ & $-28.3 \pm 1.0$ & 3 & $15.1 \pm 3.3$ & $8.6 \pm 1.7$ & $0.7 \pm 0.7$ & $7.6 \pm 2.3$ & $18.5 \pm 2.7$ & $1.3 \pm 0.3$ & 10 \\
\hline & & & $N$ & $-28.8 \pm 0.3$ & 3 & $14.8 \pm 5.2$ & $8.7 \pm 2.1$ & $1 \pm 0.9$ & $6.9 \pm 2.1$ & $19.9 \pm 5.5$ & $1.5 \pm 0.6$ & 12 \\
\hline & & autumn & G & $-28.3 \pm 0.9$ & 4 & $14.6 \pm 3.3$ & $7 \pm 2$ & $0.6 \pm 0.5$ & $6.7 \pm 1.3$ & $16.3 \pm 3.5$ & $1.2 \pm 0.3$ & 13 \\
\hline & & & $\mathrm{N}$ & $-27.7 \pm 0.9$ & 4 & $17 \pm 4.8$ & $10.4 \pm 3.6$ & $0.9 \pm 1$ & $5.4 \pm 1.6$ & $17.4 \pm 5$ & $1.3 \pm 0.4$ & 10 \\
\hline \multirow{3}{*}{\multicolumn{2}{|c|}{ Terrestrial insect }} & spring & & $-27.9 \pm 1.0$ & 4 & $14.6 \pm 3.4$ & $7 \pm 4.9$ & $0 \pm 0$ & $0.3 \pm 0.1$ & $0.5 \pm 0.2$ & $0.5 \pm 0.2$ & 3 \\
\hline & & summer & & $-28.4 \pm 0.4$ & 4 & $13 \pm 4.3$ & $5 \pm 0.6$ & $0 \pm 0$ & $1.1 \pm 1.1$ & $2.2 \pm 1.9$ & $0.5 \pm 0.2$ & 3 \\
\hline & & autumn & & $-29.1 \pm 0.3$ & 4 & $8.8 \pm 1$ & $1.7 \pm 0.2$ & $0 \pm 0$ & $0.5 \pm 0.3$ & $0.7 \pm 0.2$ & $0.3 \pm 0$ & 3 \\
\hline \multirow[t]{12}{*}{ Riparian predator } & \multirow[t]{6}{*}{ ground spider } & spring & G & $-27.8 \pm 0.5$ & 13 & $17 \pm 3$ & $3 \pm 1.2$ & $0.1 \pm 0.5$ & $7.3 \pm 2.3$ & $20.3 \pm 4.2$ & $1 \pm 0.2$ & 12 \\
\hline & & & $\mathrm{N}$ & $-27.4 \pm 0.5$ & 12 & $15 \pm 4.2$ & $3 \pm 1$ & $0.4 \pm 0.9$ & $7.2 \pm 3$ & $20.7 \pm 7.7$ & $1.1 \pm 0.4$ & 11 \\
\hline & & summer & G & $-28.1 \pm 0.6$ & 15 & $15.9 \pm 4.4$ & $2.8 \pm 2.2$ & $0.2 \pm 0.4$ & $7.1 \pm 3.2$ & $16.7 \pm 5.6$ & $0.9 \pm 0.3$ & 12 \\
\hline & & & $\mathrm{N}$ & $-28.0 \pm 0.8$ & 12 & $16.7 \pm 6.5$ & $5.1 \pm 2.3$ & $0.4 \pm 0.8$ & $5.7 \pm 2.1$ & $12.8 \pm 7.8$ & $1 \pm 0.7$ & 12 \\
\hline & & autumn & G & $-28.5 \pm 0.6$ & 8 & $16.5 \pm 3.8$ & $4.6 \pm 1.7$ & $0.5 \pm 0.7$ & $3.9 \pm 2.2$ & $10.3 \pm 5.5$ & $0.8 \pm 0.4$ & 12 \\
\hline & & & $\mathrm{N}$ & $-27.7 \pm 0.4$ & 12 & $14.4 \pm 4.7$ & $5.1 \pm 2.3$ & $0.4 \pm 0.7$ & $4.8 \pm 3$ & $13.2 \pm 7.5$ & $1 \pm 0.5$ & 12 \\
\hline & \multirow[t]{6}{*}{ web spider } & spring & G & $-28.7 \pm 1.2$ & 12 & $16.2 \pm 4.3$ & $3.2 \pm 1.2$ & $1.5 \pm 1.8$ & $2 \pm 1.4$ & $19.7 \pm 4.2$ & $1.5 \pm 0.6$ & 12 \\
\hline & & & $\mathrm{N}$ & $-28.7 \pm 0.5$ & 7 & $11.5 \pm 6.4$ & $5.7 \pm 2.1$ & $6.5 \pm 3.9$ & $1.7 \pm 1.2$ & $19.9 \pm 3.5$ & $3.2 \pm 2.7$ & 9 \\
\hline & & summer & G & $-28.7 \pm 1.3$ & 11 & $14.7 \pm 4.4$ & $4.6 \pm 1.4$ & $0.3 \pm 0.5$ & $4.8 \pm 2.1$ & $17.2 \pm 4.4$ & $1.2 \pm 0.5$ & 12 \\
\hline & & & N & $-28.0 \pm 0.8$ & 11 & $15.1 \pm 5.5$ & $5.2 \pm 1.1$ & $0.5 \pm 0.8$ & $3.2 \pm 1.8$ & $15.5 \pm 6.4$ & $1.4 \pm 0.8$ & 12 \\
\hline & & autumn & G & $-28.3 \pm 1.0$ & 10 & $21.7 \pm 5.6$ & $4.7 \pm 2.6$ & $0.3 \pm 0.6$ & $3 \pm 1.7$ & $8.3 \pm 4.8$ & $0.6 \pm 0.3$ & 12 \\
\hline & & & $\mathrm{N}$ & $-28.0 \pm 0.8$ & 10 & $17 \pm 4$ & $2.9 \pm 1.2$ & $0.4 \pm 1.1$ & $1.7 \pm 0.9$ & $6.5 \pm 4.6$ & $0.6 \pm 0.6$ & 12 \\
\hline
\end{tabular}




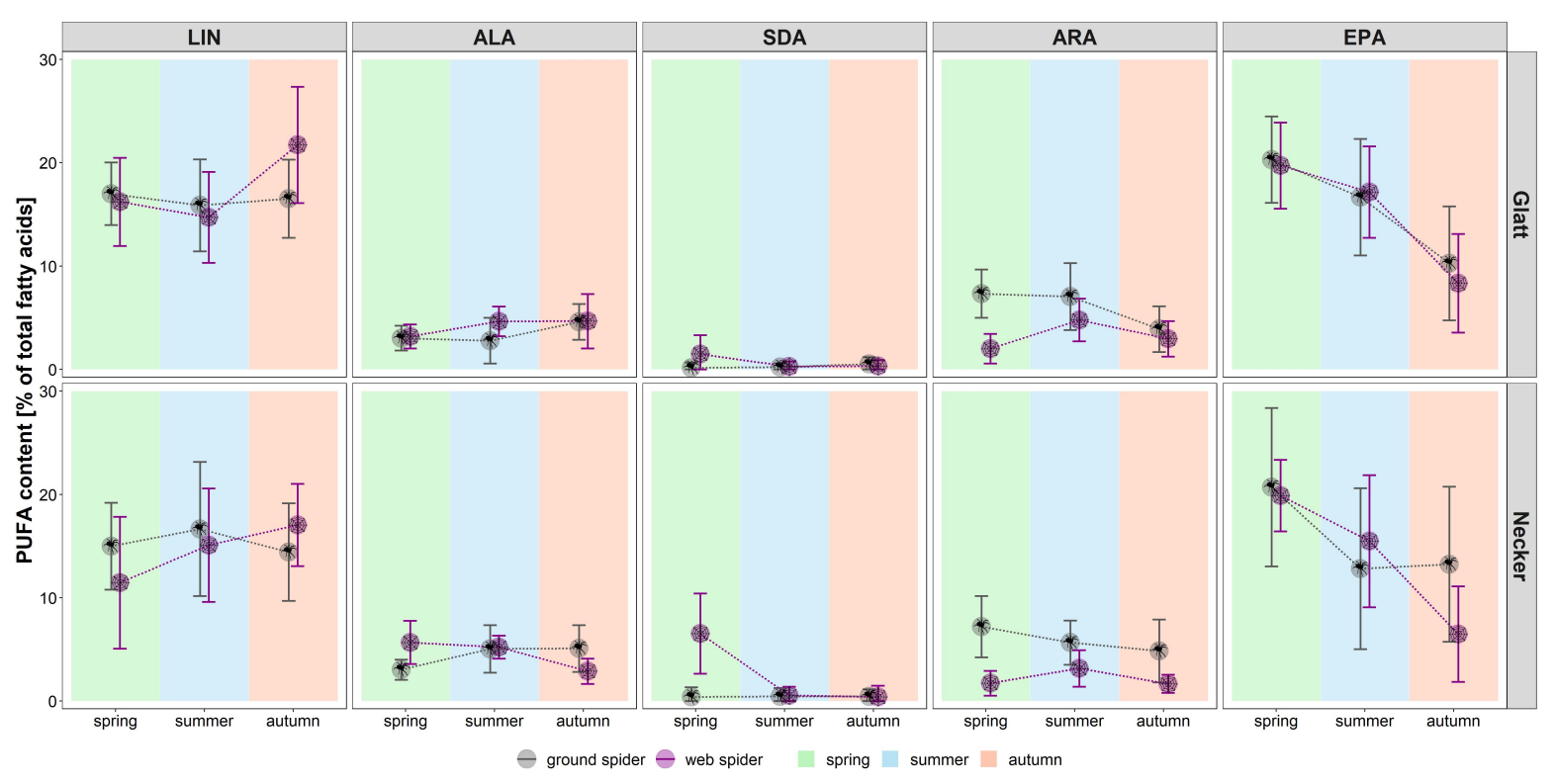

FIGURE 2 | Individual PUFA content (as \% of total fatty acids) in web spiders $(n=69)$ and ground spiders $(n=71)$ separated by stream and season. Points represent mean content, and error bars represent standard deviation, background colors represent the three seasons (spring, summer, and autumn).

content was significantly higher in web spiders than in ground spiders, but only in spring. The differences in LIN and ALA between spider types were specific to season and fluvial system. For EPA, we found no significant difference between spider types. Between the two systems the only overall significant difference was a slightly higher LIN content in riparian spiders at the Glatt. In spring, we found a higher SDA content and $\Sigma \omega 3 / \Sigma \omega 6$ ratio in web spiders than ground spiders at the Glatt than at the Necker (Table 2).

\section{PUFA Transfer Across Trophic Levels}

Individual PUFA content in periphyton and emergent aquatic insects showed site and season specific differences (see Supplementary Figure 1). Therefore, a different PUFA pool was available for riparian spiders at different sites and seasons. EPA generally made up the largest proportion of Polyunsaturated fatty acids in both periphyton and emergent aquatic insects.

The mixed effects model indicated average ALA content in periphyton was a moderate predictor for ALA content in aquatic Diptera $\left(R^{2} \mathrm{~m}=0.31, p<0.05\right)$ (Figure 3A). Model results showed SDA content in periphyton was a strong predictor for SDA content in aquatic Diptera $\left(R^{2} \mathrm{~m}=0.51, p<0.001\right)$ and Plecoptera $\left(R^{2} \mathrm{~m}=0.53, p<0.05\right)$. LIN content in Diptera $\left(R^{2} \mathrm{~m}=0.22, p=0.05\right)$ and ALA content in Ephemeroptera $\left(R^{2} \mathrm{~m}=0.15, p>0.05\right)$ were weak predictors for the respective PUFAs in riparian web spiders. Average SDA and ARA in emergent aquatic insects of all orders were a predictor for SDA (Diptera: $R^{2} \mathrm{~m}=0.47, p=0.01$; Ephemeroptera: $R^{2} \mathrm{~m}=0.1$, $p=0.08$ ); Plecoptera: $R^{2} \mathrm{~m}=0.57, p<0.001$ ) and ARA (Diptera: $R^{2} \mathrm{~m}=0.49, p<0.05$; Ephemeroptera: $R^{2} \mathrm{~m}=0.19, p<0.05$; Plecoptera: $\left.R^{2} \mathrm{~m}=0.20, p>0.05\right)$ content in web spiders (Figure 3B). For the other PUFAs, the variance explained by the lower trophic level was close to zero $\left(R^{2} \mathrm{~m}<0.1, p>0.05\right)$. Individual PUFAs of emergent aquatic insect had low predictive power for PUFAs in ground spiders $\left(R^{2} \mathrm{~m}<0.1, p>0.05\right)$ (Figure 3B). There was only a weak predictive effect of ALA in Diptera $\left(R^{2} \mathrm{~m}=0.17, p<0.05\right)$ and ARA in Ephemeroptera $\left(R^{2} \mathrm{~m}=0.10, p=0.055\right)$.

\section{Multivariate Analysis of Similarity}

Multivariate comparisons of similarity revealed seasonal differences in PUFA profiles for both spider types. Web spiders in spring were clearly separated from those in summer and autumn (seasonal effect: ANOSIM: $R=0.31, p=0.001$ ) (Figure 4A), and the difference was more pronounced at the Necker. Ground spiders also showed some, albeit less pronounced, seasonal differences (ANOSIM: $R=0.15, p=0.001$ ) (Figure 4A). PUFA profiles of web spiders and ground spiders differed in spring ( $R=0.46, p=0.001)$, and the difference was more pronounced at the Necker $(R=0.60, p=0.001)$ than the Glatt $(R=0.36$, $p=0.001)$. In contrast, the two spider types had similar PUFA profiles in summer $(R=0.04, p=0.051)$ and autumn $(R=0.12$, $p=0.004$ ) in both rivers (Figure $4 \mathbf{B}$ and Table 3 ). Lastly, web spiders showed some differentiation between streams in spring $(R=0.21, p=0.015)$.

Web spider PUFA profiles were most similar to those of emergent aquatic insects, especially Diptera (ANOSIM spring: $R=0.07, p=0.085$, summer: $R=0.14, p=0.001$ ) and Plecoptera at both rivers in spring and summer, but were well separated from terrestrial reference samples (ANOSIM spring: $R=0.94$, $p=0.001$, summer: $R=0.77, P=0.001$ ) (Figure 5 and Table 3). In autumn, web spiders were more separate from all emergent aquatic insect groups (Diptera: ANOSIM $R=0.46 p=0.001$; Plecoptera: ANOSIM $R=0.53, \mathrm{p}=0.001$; Ephemeroptera: 
TABLE 2 | Factorial ANOVA of PUFA content in riparian spiders (factors: spider type = type, season, fluvial system = river) and significant post hoc comparisons (web, web spider; ground, ground spider; N, Necker; G, Glatt).

\begin{tabular}{|c|c|c|c|c|c|c|c|c|c|c|}
\hline & Factor & Df & $F$-value & $\operatorname{Pr}(>F)$ & contrast & season & type & river & t.ratio & $p$ \\
\hline \multirow[t]{7}{*}{ LIN } & type & 1 & 0.54 & 0.465 & & & & & & \\
\hline & season & 1 & 7.48 & $0.007^{\star \star}$ & spring-autumn & & & & -2.6 & 0.0270 \\
\hline & river & 2 & 3.17 & $0.045^{\star}$ & $G-N$ & & & & 2.7 & 0.0071 \\
\hline & type:season & 1 & 1.65 & 0.202 & & & & & & \\
\hline & type:river & 2 & 2.52 & 0.084 & & & & & & \\
\hline & season:river & 2 & 2.64 & 0.075 & & & & & & \\
\hline & type:season:river & 2 & 0.44 & 0.648 & & & & & & \\
\hline \multirow[t]{14}{*}{ ALA } & type & 1 & 4.65 & $0.033^{*}$ & & & & & & \\
\hline & season & 2 & 4.23 & $0.017^{\star}$ & & & & & & \\
\hline & river & 1 & 5.85 & $0.017^{\star}$ & & & & & & \\
\hline & type:season & 2 & 3.92 & $0.022^{*}$ & & & & & & \\
\hline & type:river & 1 & 1.23 & 0.269 & & & & & & \\
\hline & season:river & 2 & 4.45 & $0.014^{\star}$ & & & & & & \\
\hline & type:season:river & 2 & 4.48 & $0.013^{*}$ & summer - autumn & & ground & G & -3.4 & 0.003 \\
\hline & & & & & spring - autumn & & web & $\mathrm{N}$ & 2.9 & 0.018 \\
\hline & & & & & summer - autumn & & web & $\mathrm{N}$ & 2.8 & 0.018 \\
\hline & & & & & ground - web & summer & & G & -3.5 & 0.0006 \\
\hline & & & & & ground - web & spring & & $\mathrm{N}$ & -2.6 & 0.010 \\
\hline & & & & & ground- web & autumn & & $\mathrm{N}$ & 2.5 & 0.012 \\
\hline & & & & & $G-N$ & spring & web & & -2.7 & 0.007 \\
\hline & & & & & $\mathrm{G}-\mathrm{N}$ & summer & ground & & -3.5 & 0.0005 \\
\hline \multirow[t]{11}{*}{ SDA } & type & 1 & 1.50 & 0.223 & & & & & & \\
\hline & season & 2 & 0.70 & 0.5 & & & & & & \\
\hline & river & 1 & 7.90 & $0.006^{\star \star}$ & & & & & & \\
\hline & type:season & 2 & 3.61 & $0.03^{\star}$ & & & & & & \\
\hline & type:river & 1 & 5.70 & $0.018^{*}$ & & & & & & \\
\hline & season:river & 2 & 6.52 & $0.002^{\star \star}$ & & & & & & \\
\hline & type:season:river & 2 & 4.02 & $0.02^{\star}$ & spring - summer & & web & $\mathrm{N}$ & 7.1 & $2.7 e-10$ \\
\hline & & & & & spring - autumn & & web & $\mathrm{N}$ & 7.7 & $9.6 e-12$ \\
\hline & & & & & ground - web & spring & & G & -2.9 & 0.005 \\
\hline & & & & & ground - web & spring & & $\mathrm{N}$ & -7.5 & $1.03 e-11$ \\
\hline & & & & & $G-N$ & spring & web & & -5.5 & $1.7 \mathrm{e}-07$ \\
\hline \multirow[t]{13}{*}{ ARA } & type & 1 & 28.81 & $3.62 \mathrm{e}-7^{\star \star \star}$ & & & & & & \\
\hline & season & 2 & 7.20 & $0.001^{\star \star}$ & & & & & & \\
\hline & river & 1 & 3.04 & 0.083 & & & & & & \\
\hline & type:season & 2 & 6.76 & $0.002^{\star \star \star}$ & ground - web & spring & & & 8.2 & $2.5 e-13$ \\
\hline & & & & & ground - web & summer & & & 3.4 & $8.1 \mathrm{e}-04$ \\
\hline & & & & & ground - web & autumn & & & 3.6 & $4.6 \mathrm{e}-04$ \\
\hline & & & & & spring-autumn & & ground & & 3.9 & 0.0005 \\
\hline & & & & & summer-autumn & & ground & & 2.8 & 0.015 \\
\hline & & & & & spring-summer & & web & & -3.9 & 0.0005 \\
\hline & & & & & summer-autumn & & web & & 3.0 & 0.0010 \\
\hline & type:river & 1 & 1.98 & 0.162 & & & & & & \\
\hline & season:river & 2 & 1.06 & 0.35 & & & & & & \\
\hline & type:season:river & 2 & 0.80 & 0.453 & & & & & & \\
\hline \multirow[t]{9}{*}{ EPA } & type & 1 & 0.26 & 0.608 & & & & & & \\
\hline & season & 2 & 19.19 & $5.15 e-8^{\star \star \star}$ & spring-summer & & & & 3.4 & $2.2 \mathrm{e}-03$ \\
\hline & & & & & spring-autumn & & & & 8.1 & $1.2 \mathrm{e}-12$ \\
\hline & & & & & summer-autumn & & & & 4.8 & $1.4 \mathrm{e}-05$ \\
\hline & river & 1 & 1.04 & 0.309 & & & & & & \\
\hline & type:season & 2 & 0.36 & 0.695 & & & & & & \\
\hline & type:river & 1 & 0.08 & 0.776 & & & & & & \\
\hline & season:river & 2 & 1.45 & 0.239 & & & & & & \\
\hline & type:season:river & 2 & 1.60 & 0.205 & & & & & & \\
\hline \multirow[t]{14}{*}{$\Sigma \omega 3 / \Sigma \omega 6$ ratio } & type & 1 & 1.53 & 0.218 & & & & & & \\
\hline & season & 2 & 6.53 & $0.002^{\star \star}$ & & & & & & \\
\hline & river & 1 & 6.03 & $0.015^{\star}$ & & & & & & \\
\hline & type:season & 2 & 2.12 & 0.124 & & & & & & \\
\hline & type:river & 1 & 0.98 & 0.325 & & & & & & \\
\hline & season:river & 2 & 3.00 & 0.053 & & & & & & \\
\hline & type:season:river & 2 & 3.40 & $0.036^{\star}$ & spring - autumn & & web & G & 3.8 & 0.0006 \\
\hline & & & & & summer - autumn & & web & G & 3.0 & 0.009 \\
\hline & & & & & spring - summer & & web & $\mathrm{N}$ & 4.6 & $2.7 e-05$ \\
\hline & & & & & spring - autumn & & web & $\mathrm{N}$ & 7.8 & $5.6 e-12$ \\
\hline & & & & & summer - autumn & & web & $\mathrm{N}$ & 3.4 & 0.002 \\
\hline & & & & & ground - web & spring & & $\mathrm{N}$ & -5.1 & $1.4 \mathrm{e}-06$ \\
\hline & & & & & ground - web & autumn & & $\mathrm{N}$ & 2.4 & 0.017 \\
\hline & & & & & $G-N$ & spring & web & & -4.0 & $9.3 e-05$ \\
\hline
\end{tabular}

${ }^{*} p<0.05,{ }^{* *} p<0.01,{ }^{* *} p<0.001$. 

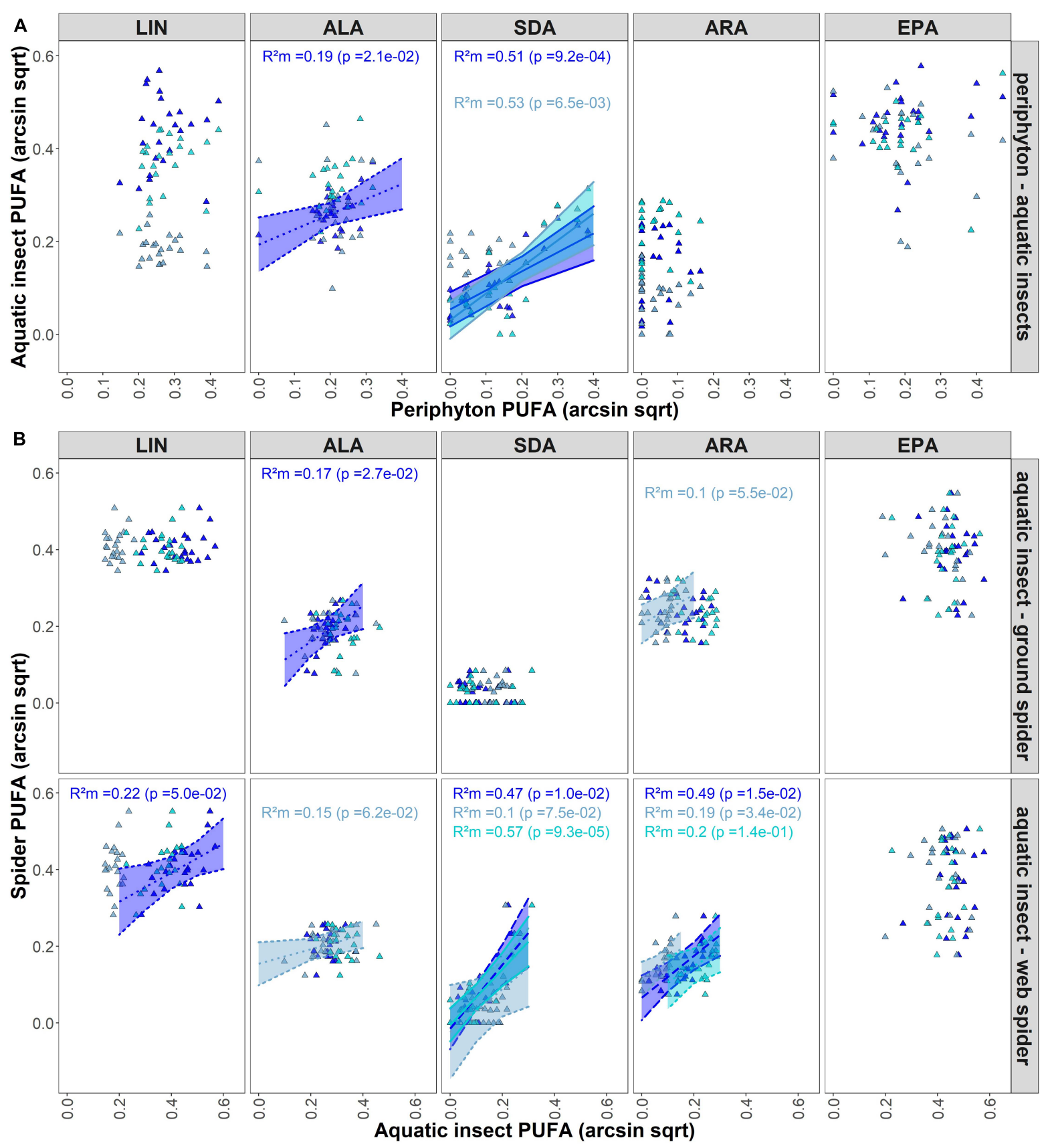

\ Diptera $\Delta$ Ephemeroptera $\Delta$ Plecoptera $\quad \cdots$ weak -- moderate $\quad$ strong

FIGURE 3 | (A) Mixed model showing effect of periphyton individual PUFA content on individual PUFA content of aquatic insects, with river and seasons as random effects. (B) Mixed model showing effect of aquatic insect individual PUFA content on individual PUFA content of riparian spiders, with river and seasons as random effects. If no trendline is shown, predictive effect of fixed effect is close to zero $\left(R^{2} m<0.1\right)$, dotted lines represents weak effects ( $\left.R^{2} m<0.3\right)$, dashed lines represent moderate effects $\left(R^{2} m<0.5\right)$ and solid lines represent strong effect $\left(R^{2} m>0.5\right)$.

ANOSIM $R=0.87, p=0.001)$ but still distinct from terrestrial insect reference samples (ANOSIM $R=0.72, p=0.001$ ).

Ground spiders were more separated from emergent aquatic insects in spring than web spiders (Figure 5 and Table 3). Ground spiders showed some overlap to aquatic Diptera (ANOSIM $R=0.59, p=0.001$ ) but were well separated from Plecoptera
(ANOSIM $R=0.75, p=0.001$ ) in spring; the overlap with Plecoptera was larger at the Glatt than Necker (Figure 5 and Table 3). In summer, ground spiders were similar to aquatic Diptera (ANOSIM $R=0.14, p=0.001$ ) and Plecoptera (ANOSIM $R=0.25, p=0.001)$. In autumn, ground spiders were most similar to Plecoptera (ANOSIM $R=0.23, p=0.001$ ) and showed 


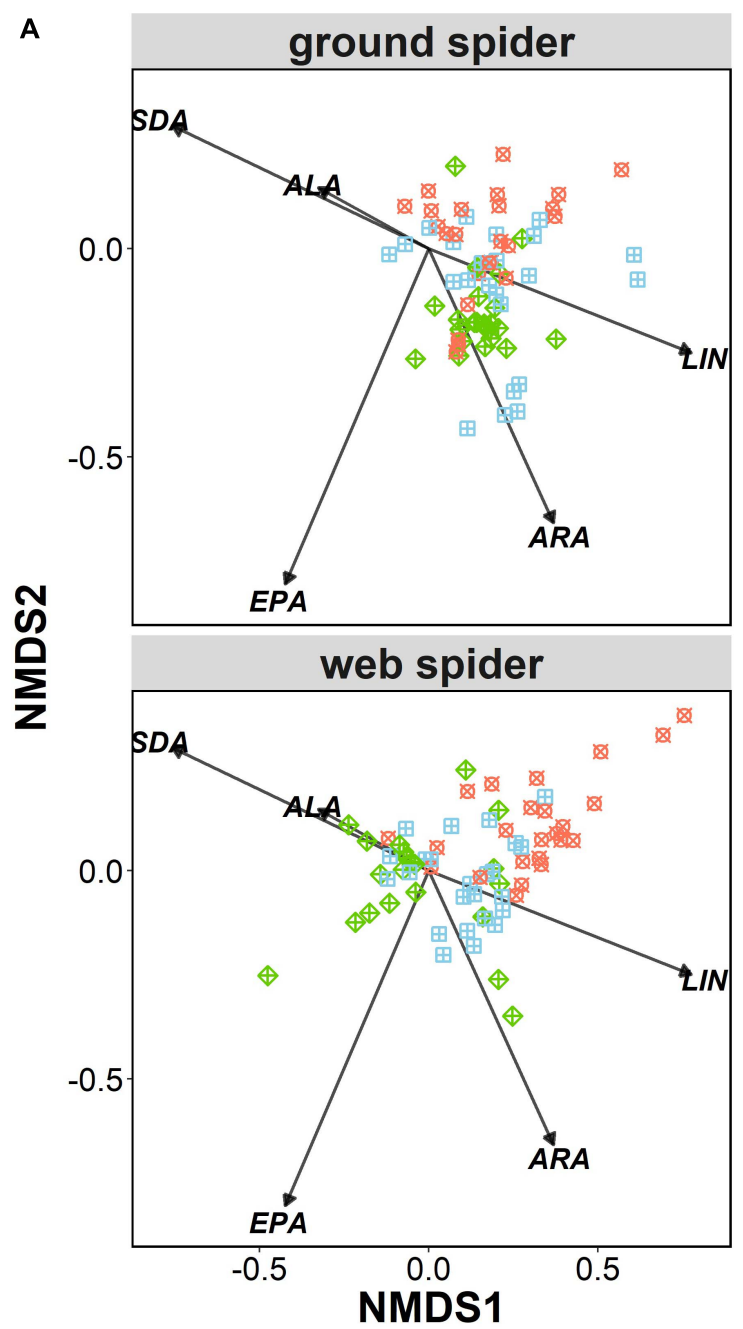

ground spider $\mathbf{w}$ web spider
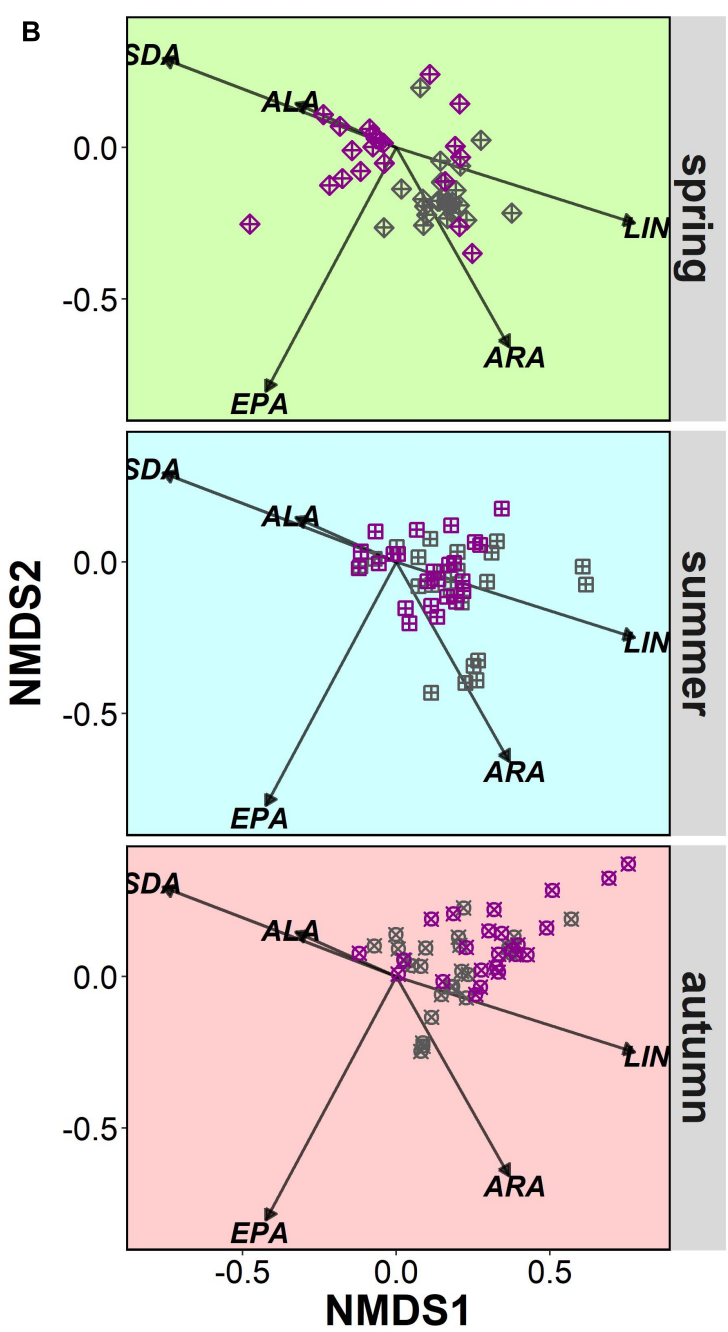

spring $\boxplus$ summer autumn

FIGURE 4 | Non-metric multidimensional scaling (nMDS) of arcsine-square-root-transformed PUFA (\% of total fatty acids) of riparian spiders. Stress level = 0.15. LIN, linolenic acid; $A L A$, alpha-linolenic acid; SDA, stearidonic acid; $A R A$, arachidonic acid; EPA, eicosapentaenoic acid. Organized by (A) seasonal differences in ground spiders and web spiders, and $(\mathbf{B})$ differences between spider types per season.

some overlap with Diptera (ANOSIM $R=0.35, p=0.001$ ). Ground spider PUFA profiles were separated from those of Ephemeroptera and terrestrial reference samples during all seasons (Figure 5 and Table $\mathbf{3}$ ).

\section{Food Source Reconstruction}

\section{Food Web Analysis Using $\delta^{13} \mathrm{C}$}

Riparian spiders had average $\delta^{13} \mathrm{C}$ ratios of $-27.9 \pm 0.6 \%$ in ground spiders and $-28.4 \pm 1.0 \%$ in web spiders. We found a significant main effect of river (ANOVA, $F=5.56, p=0.02$ ) and a close to significant interaction effect of season and spider type $(F=2.90, p=0.056)$ on $\delta^{13} \mathrm{C}$ ratios. In spring, the $\delta^{13} \mathrm{C}$ ratio of web spiders $(-28.7 \pm 0.9 \%)$ was significantly more depleted than ground spiders $(-27.6 \pm 0.5 \%$ ) (t.ratio $=5.17, p<0.001)$. In summer and autumn, web spiders and ground spiders displayed similar $\delta^{13} \mathrm{C}$ isotope ratios (web spider: summer $-28.4 \pm 1.1 \%$, autumn $-28.1 \pm 0.9 \%$; ground spider: summer: $-28.0 \pm 0.6$ $\%$, autumn: $-28.02 \pm 0.7 \% 0, p>0.05)$. There was no significant difference in $\delta^{13} \mathrm{C}$ ratio among seasons for either spider type $(p>0.05)$. However, spiders were more depleted at the Glatt than at the Necker $(p<0.05)$.

In spring, the $\delta^{13} \mathrm{C}$ ratio of web spiders $(-28.7 \pm 0.9 \%)$ was between that of aquatic $(-32.5 \pm 1.7 \% 0)$ and terrestrial $(-27.9 \pm 1.0 \%)$ insects, indicating that web spiders consumed a mixture of aquatic and terrestrial food sources (Figure 6). In contrast, ground spider $\delta^{13} \mathrm{C}$ ratios $(-27.6 \pm 0.5 \%$ ) were similar to terrestrial insects, inferring a mostly terrestrial source in the diet. The $\delta^{13} \mathrm{C}$ ratio of all groups of emergent aquatic insects were distinct from terrestrial insects in spring (t.ratio $=2.1, p<0.001$ ) but not in summer and autumn 
TABLE 3 | Pairwise Similarity (ANOSIM) of PUFA profiles of prey and predator groups at each of the systems (Necker, Glatt) and overall (both rivers).

\begin{tabular}{|c|c|c|c|c|c|c|c|c|c|c|c|c|}
\hline & \multirow[t]{2}{*}{ season } & \multirow[t]{2}{*}{ river } & \multicolumn{2}{|c|}{ ground spider } & \multicolumn{2}{|c|}{ Diptera } & \multicolumn{2}{|c|}{ Plecoptera } & \multicolumn{2}{|c|}{ Ephemeroptera } & \multicolumn{2}{|c|}{ terrestrial insect } \\
\hline & & & $\mathbf{R}$ & $\mathbf{p}$ & $\mathbf{R}$ & $\mathbf{p}$ & $\mathbf{R}$ & $p$ & $\mathbf{R}$ & $p$ & $\mathbf{R}$ & $\mathbf{p}$ \\
\hline \multirow[t]{9}{*}{ web spider } & \multirow[t]{3}{*}{ spring } & Glatt & 0.36 & 0.001 & 0.15 & 0.024 & 0.34 & 0.001 & 0.70 & 0.001 & 1.00 & 0.001 \\
\hline & & Necker & 0.60 & 0.001 & $\begin{array}{c}- \\
0.03\end{array}$ & 0.604 & 0.48 & 0.001 & 0.52 & 0.001 & 0.95 & 0.010 \\
\hline & & overall & 0.46 & 0.001 & 0.07 & 0.085 & 0.34 & 0.001 & 0.56 & 0.001 & 0.94 & 0.001 \\
\hline & \multirow[t]{3}{*}{ summer } & Glatt & 0.04 & 0.179 & 0.09 & 0.058 & 0.38 & 0.001 & 0.76 & 0.001 & 0.90 & 0.002 \\
\hline & & Necker & 0.02 & 0.316 & 0.18 & 0.022 & 0.28 & 0.002 & 0.73 & 0.001 & 0.60 & 0.001 \\
\hline & & overall & 0.04 & 0.051 & 0.14 & 0.001 & 0.31 & 0.001 & 0.74 & 0.001 & 0.77 & 0.001 \\
\hline & \multirow[t]{3}{*}{ autumn } & Glatt & 0.05 & 0.153 & 0.34 & 0.001 & 0.51 & 0.001 & 0.87 & 0.001 & 0.87 & 0.002 \\
\hline & & Necker & 0.23 & 0.004 & 0.55 & 0.001 & 0.64 & 0.001 & 0.90 & 0.001 & 0.61 & 0.008 \\
\hline & & overall & 0.12 & 0.004 & 0.46 & 0.001 & 0.53 & 0.001 & 0.87 & 0.001 & 0.72 & 0.001 \\
\hline \multirow{9}{*}{$\begin{array}{l}\text { ground } \\
\text { spider }\end{array}$} & \multirow[t]{3}{*}{ spring } & Glatt & & & 0.64 & 0.001 & 0.54 & 0.001 & 0.96 & 0.001 & 1.000 & 0.007 \\
\hline & & Necker & & & 0.63 & 0.001 & 0.95 & 0.001 & 0.96 & 0.001 & 0.97 & 0.002 \\
\hline & & overall & & & 0.59 & 0.001 & 0.75 & 0.001 & 0.96 & 0.001 & 0.99 & 0.001 \\
\hline & \multirow[t]{3}{*}{ summer } & Glatt & & & 0.14 & 0.012 & 0.27 & 0.001 & 0.85 & 0.001 & 0.75 & 0.005 \\
\hline & & Necker & & & 0.15 & 0.022 & 0.20 & 0.004 & 0.75 & 0.001 & 0.47 & 0.025 \\
\hline & & overall & & & 0.14 & 0.002 & 0.25 & 0.001 & 0.78 & 0.001 & 0.60 & 0.001 \\
\hline & \multirow[t]{3}{*}{ autumn } & Glatt & & & 0.31 & 0.001 & 0.22 & 0.001 & 0.84 & 0.001 & 0.90 & 0.001 \\
\hline & & Necker & & & 0.35 & 0.001 & 0.24 & 0.011 & 0.92 & 0.001 & 0.99 & 0.003 \\
\hline & & overall & & & 0.35 & 0.001 & 0.23 & 0.001 & 0.86 & 0.001 & 0.94 & 0.001 \\
\hline
\end{tabular}

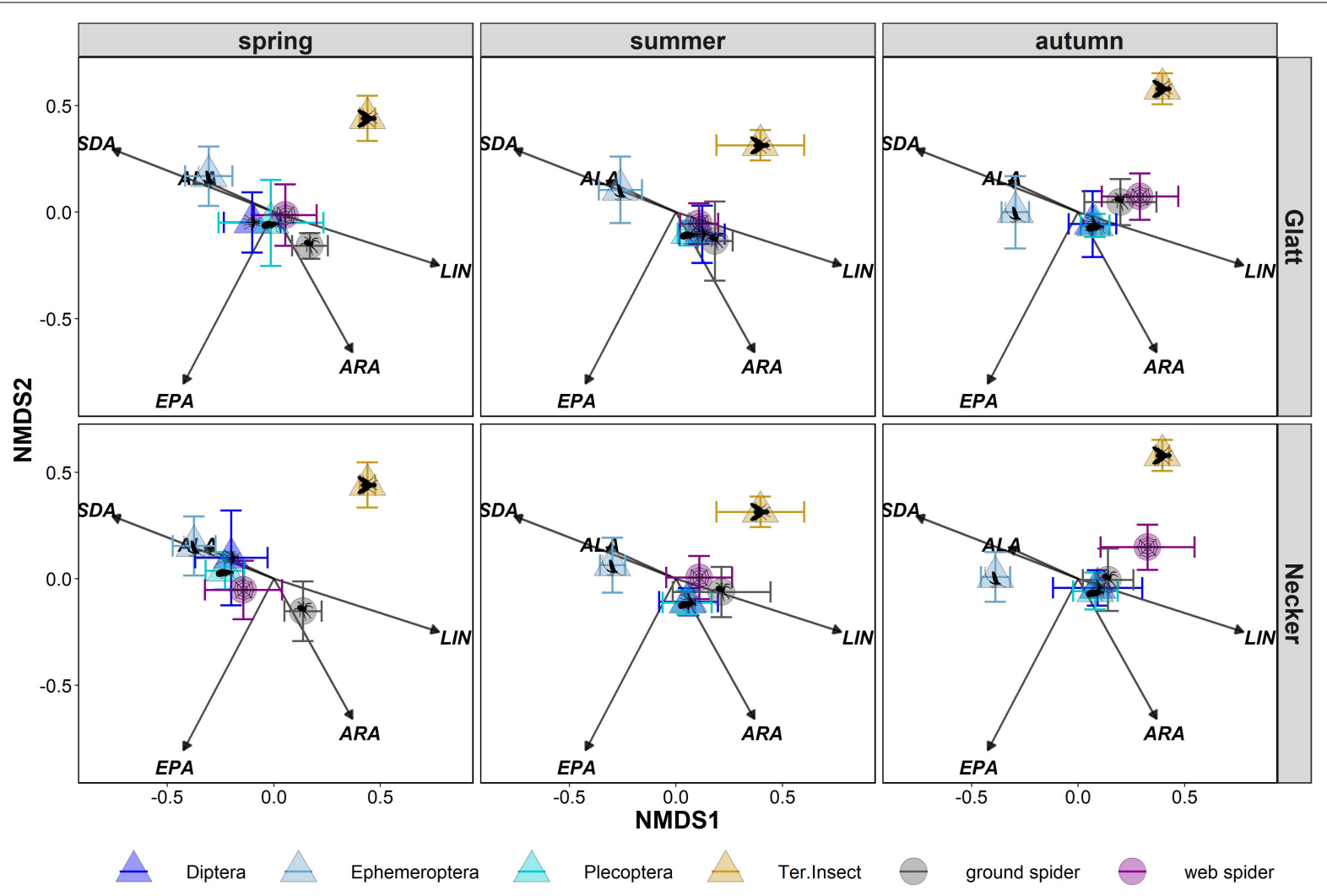

FIGURE 5 | Non-metric multidimensional scaling (nMDS) of arcsine-square-root-transformed PUFA (\% of total fatty acids) of prey (aquatic Diptera, Ephemeroptera, Plecoptera and terrestrial insects) and predator groups (web spiders, ground spiders). Stress level $=0.15$. Points represent means and error bars represent standard deviation. Results were divided post hoc by stream and season. LIN, linolenic acid; ALA, alpha-linolenic acid; SDA, stearidonic acid; ARA, arachidonic acid; EPA, eicosapentaenoic acid. 
(Diptera and Plecoptera overlapped with terrestrial insects); thus the proportion of aquatic-derived carbon in spiders was only calculated in spring. Based on mixing model results (Equation 2), web spiders obtained on average $38 \%$ aquatic-derived carbon at the Glatt and $44 \%$ at the Necker in spring. In contrast, ground spiders obtained on average $19 \%$ of aquatic-derived carbon at the Glatt and $13 \%$ at the Necker. The difference in proportion of carbon obtained from aquatic sources in spring was more pronounced between spider types at the Necker.

\section{Including PUFAs in Food Source Reconstruction}

The $\delta^{13} \mathrm{C}$ ratio and PUFA profiles of spiders changed with distance from the shore. The $\delta^{13} \mathrm{C}$ ratio of spiders had a more aquatic signature close to the shoreline $(0-2 \mathrm{~m})$ than $40-50 \mathrm{~m}$ away from the shore (Table 4 and Figure 7A). The correlation between distance and $\delta^{13} \mathrm{C}$ ratio was significant for ground spiders (GAM $p=0.007$ ) with a trend to less depleted values further from the shoreline, also the direct comparison between 0-2 $\mathrm{m}$ and $40-50 \mathrm{~m}$ showed a difference that was close to significance $(p=0.052)$. A multivariate comparison of similarities showed that PUFA profiles of spiders sampled 0-2 $\mathrm{m}$ from shore were separated from those spiders sampled further away from shore (ground spiders: ANOSIM $R=0.99, p=0.008$; web spiders: ANOSIM $R=0.62, p=0.012$ ). We found higher EPA and SDA content close to shore and decreasing values with distance (Table 4), the difference between $0-2 \mathrm{~m}$ and $40-50 \mathrm{~m}$ being significant for both spider types for SDA $(p<0.05)$ but not EPA $(p>0.05)$ (Figure 7A). The GAM trend line also showed decreasing content with distance, but the correlation was not significant $(p>0.05)$ (Figure 7A). A decrease in ALA content with distance from shore was evident for ground spiders (GAM $p<0.05$ ), but not web spiders (GAM $p>0.05$ ) (Table 4 and Figure 7A). Both LIN and ARA increased with distance from shore (LIN: both spider types GAM $p<0.05$; ARA: ground spiders GAM $p<0.05)$. LIN in both spider types increased from $\sim 10 \%(0-2 \mathrm{~m})$ to nearly $25 \%$ of total fatty acids at $40-50 \mathrm{~m}$ distance from shore (Figure 7A and Table 4). The $\Sigma \omega 3 / \Sigma \omega 6$ ratio differed between $0-2 \mathrm{~m}$ (web spider: $1.3 \pm 0.6$, ground spider: $1.7 \pm 0.4$ ) and $40-50 \mathrm{~m}$ (web spider: $0.7 \pm 0.1, p=0.069$; ground spider: $0.3 \pm 0.1, p=0.002$ ), although this difference was significant only for ground spiders.

The compound-specific $\delta^{13} \mathrm{C}$ ratio of $\mathrm{C} 18$ fatty acids was less depleted in terrestrial insects (mean $\delta^{13} \mathrm{C}=-34.8 \pm 0.9 \%$ ) than in aquatic insects $\left(\delta^{13} \mathrm{C}=-39.3 \pm 3.5 \%\right.$ ) (Figure 7B). The $\delta^{13} \mathrm{C}$ ratios of $\mathrm{C} 18$ fatty acids of aquatic and terrestrial insects were used as baselines for comparison with spider $\delta^{13} \mathrm{C}$ ratio. Like the bulk isotope ratio, $\mathrm{C} 18 \delta^{13} \mathrm{C}$ ratio of spiders was between aquatic and terrestrial insects with ground spiders $\left(\delta^{13} \mathrm{C}=-35.1 \% 0\right)$ being close to terrestrial insects. In contrast, spider $\delta^{13} \mathrm{C}$ ratios of C20 s were close to the aquatic baseline (web spider: $-38.6 \%$, ground spider: $-38.1 \%$ ). The main part of C20 fatty acids consisted of EPA (web spiders: 80-90\%, ground spiders: 50-90\%) and the rest was ARA. The sample containing the most ARA was least depleted (Supplementary Tables 2, 3). This indicates $\delta^{13} \mathrm{C}$ of EPA in spiders was similar to $\delta^{13} \mathrm{C}$ ratio of fatty acids in aquatic insects, while ARA might have a more terrestrial $\delta^{13} \mathrm{C}$ signature. This is in accordance with the results from the distance gradient were ARA was increasing with distance from shore while EPA was decreasing. We found no indication for internal metabolism of EPA or acquisition through terrestrial sources, EPA was therefore used for the food source reconstruction.

Based on the results above, we used LIN, ALA, SDA, and EPA as tracers for food source reconstruction. ARA was excluded for ground spiders because of potential internal production or an unknown diet source. Model output using combination of the remaining PUFAs and $\delta^{13} \mathrm{C}$ indicated a mixed diet, consisting of terrestrial and aquatic insects for both types of riparian spiders (Figure 8). Results are presented as median and 95\% credibility interval.

For web spiders, the model revealed that the diet in spring was dominated by terrestrial insects (Glatt: 45 (31-57)\%, Necker: 43 (34-52)\%), aquatic Diptera (Glatt: 35 (11-63)\%, Necker: 17 (026)\%) and Plecoptera (Glatt: 16 (0-31)\%, Necker: 34 (9-59)\%). In summer, the proportion of terrestrial insects and Diptera was lower than in spring at the Glatt (terrestrial insects: 35 (17-54)\%, Diptera: 25 (4-51)\%) while Plecoptera increased (33 (8-59)\%). At the Necker, the proportion of terrestrial insects remained similar as in spring $(44(28-61) \%)$, whereas the contribution of Diptera increased (31 (8-58)\%) while Plecoptera decreased (19 (0-43)\%). In autumn, terrestrial insects comprised the largest proportion of web spider diet at both rivers (Glatt: 51 (39-62)\%, Necker: 69 (59-77)\%) followed by Plecoptera (Glatt: 30 (10-51)\%, Necker: 9 (0-24)\%) and Diptera (Glatt: 18 (0-31)\%, Necker: 20 (4-33)\%).

For ground spiders, the diet in spring was dominated by terrestrial insects (Glatt: 79 (56-91)\%, Necker: 86 (70-94)\%). Terrestrial insect contribution was lower at both rivers in summer (Glatt: 49 (11-81)\%, Necker: 53 (30-70)\%) and autumn (Glatt: 45 (33-57)\%, Necker: 47 (35-58)\%). In summer, Plecoptera (Glatt: 25 (1-76)\%, Necker: $12(0-43) \%)$ and Diptera (Glatt: 18 (0-37)\%, Necker: 28 (3-57)\%) made up the largest proportion of aquatic prey. In autumn, Plecoptera were the most important aquatic dietary contribution for ground spiders at both rivers (Glatt: 31 (12-48)\%, Necker: 31 (18-46)\%). Ephemeroptera were estimated to contribute only small proportions $(<10 \%)$ to spider diets.

\section{DISCUSSION}

\section{PUFA Transfer}

We show here that PUFAs are transferred across ecosystem boundaries, from streams to adjacent terrestrial habitats, via emergent aquatic insects and that these PUFAs are partially incorporated into riparian spider tissues. Riparian spiders had an unusually high EPA content and thus high $\Sigma \omega 3 / \Sigma \omega 6$ ratio for terrestrial consumers. On average, EPA represented $15 \%$ of total fatty acids in riparian spiders (ca. $10 \mathrm{mg} / \mathrm{g}$ dry mass). High EPA content in riparian spiders was also reported by other studies (Fritz et al., 2017; Ramberg et al., 2020), although our results show even higher EPA content than e.g., the 2-3 mg/g dry mass found by Ramberg et al. (2020). The $\Sigma \omega 3 / \Sigma \omega 6$ ratio is often employed to distinguish autochthonous versus allochthonous food sources in aquatic food webs and to assess the relative consumption of aquatic versus terrestrial material by consumers. A ratio $>1$ is thought to indicate that dietary energy was acquired mainly 


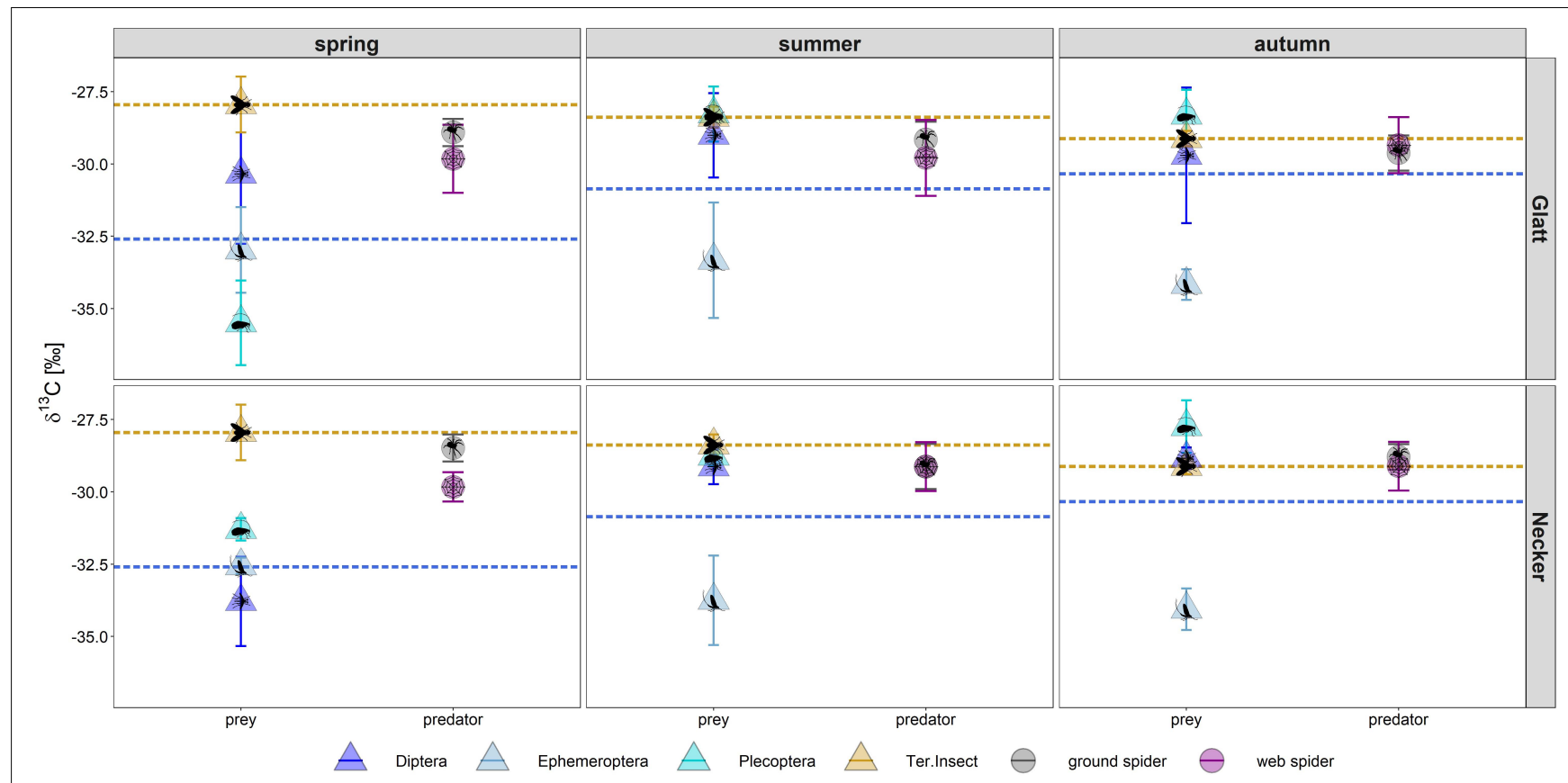

FIGURE $6 \mid \delta^{13} \mathrm{C}$ ratio of emergent insects, terrestrial insects and riparian spiders. Dashed lines represent average ratios for aquatic insects (blue) and terrestrial insects (orange). Error bars represent standard deviations. For number of samples per group see Table 1. To adjust for fractionation between trophic levels, $\mathrm{TEF}=1.1 \%$ was subtracted from predator $\delta^{13} \mathrm{C}$. On the left side of the plot are prey values, on the right site are predator values.

TABLE $4 \mid \delta^{13} \mathrm{C}$, individual PUFA content (\% of total fatty acids) and $\Sigma \omega 3 / \Sigma \omega 6$ ratio (mean \pm standard deviation) in spiders at different distances from shore (site N4).

\begin{tabular}{|c|c|c|c|c|c|c|c|c|c|}
\hline & distance & $\delta^{13} \mathrm{C}$ & LIN & ALA & SDA & ARA & EPA & $\Sigma \omega 3 / \Sigma \omega 6$ & $\mathbf{n}$ \\
\hline \multirow[t]{4}{*}{ ground spider } & $0-2 m$ & $-28.4 \pm 1.0$ & $11.2 \pm 2.0$ & $7.2 \pm 2.2$ & $2.7 \pm 2.8$ & $1.6 \pm 0.4$ & $11.2 \pm 1.1$ & $1.7 \pm 0.4$ & 3 \\
\hline & 5-10m & $-26.7 \pm 0.3$ & $23.7 \pm 0.5$ & $4.4 \pm 0.8$ & $0.8 \pm 0.3$ & $4.4 \pm 1.7$ & $10.8 \pm 3.9$ & $0.6 \pm 2$ & 3 \\
\hline & $20-30 m$ & $-27.0 \pm 0.3$ & $25.8 \pm 5.6$ & $1.8 \pm 1.7$ & $0.0 \pm 0.0$ & $5.7 \pm 0.5$ & $9.5 \pm 0.8$ & $0.4 \pm 1$ & 3 \\
\hline & $40-50 m$ & $-26.0 \pm 0.3$ & $24.3 \pm 2.3$ & $2.1 \pm 0.3$ & $0.0 \pm 0.0$ & $7.8 \pm 2.2$ & $8.2 \pm 1.4$ & $0.3 \pm 03$ & 3 \\
\hline \multirow[t]{4}{*}{ web spider } & $0-2 m$ & $-28.2 \pm 1.6$ & $13.8 \pm 3.2$ & $4.4 \pm 1.8$ & $1.9 \pm 1.1$ & $2.5 \pm 1.2$ & $13.8 \pm 6.0$ & $1.3 \pm 0.6$ & 3 \\
\hline & 5-10m & $-28.5 \pm 1.9$ & $20.3 \pm 7.4$ & $5.6 \pm 1.9$ & $0.4 \pm 0.7$ & $3.0 \pm 0.7$ & $10.0 \pm 3.2$ & $0.8 \pm 0.5$ & 3 \\
\hline & $20-30 m$ & $-27.3 \pm 0.4$ & $27.9 \pm 2.3$ & $5.3 \pm 4.6$ & $0.0 \pm 0.0$ & $3.2 \pm 1.1$ & $9.5 \pm 3.6$ & $0.5 \pm 0.1$ & 2 \\
\hline & $40-50 m$ & $-27.0 \pm 0.2$ & $23.1 \pm 2.2$ & $7.1 \pm 2.5$ & $0.0 \pm 0.0$ & $4.1 \pm 1.3$ & $10.4 \pm 4.5$ & $0.6 \pm 0.5$ & 3 \\
\hline
\end{tabular}

from autochthonous food sources (Torres-Ruiz et al., 2007; Guo et al., 2016). Most terrestrial organisms are estimated to have an average $\Sigma \omega 3 / \Sigma \omega 6$ ratio of 0.6 (Hixson et al., 2015). In the present study the $\Sigma \omega 3 / \Sigma \omega 6$ ratio was close to 1 in most spiders and even $>1$ in web spiders in spring and summer, suggesting that aquatic-derived material was a major energy source for riparian spiders.

The high $\Sigma \omega 3 / \Sigma \omega 6$ ratio of riparian spiders implies a trophic transfer of $\omega 3$-PUFAs from periphyton via emergent aquatic insects to riparian spiders. We cannot exclude, however, that spiders converted PUFAs internally from dietary precursor PUFAs or used PUFAs from terrestrial sources; e.g., some terrestrial plants produce ALA and SDA especially in seeds (Callaway et al., 1997; Guil-Guerrero, 2007) and EPA may be produced in the soil food web (Menzel et al., 2018). However, the site-specific differences that we observed for individual PUFAs, that were consistent through all trophic levels, support the idea of trophic PUFA transfer across the ecosystem boundary. For fatty acids that are primarily found in aquatic systems (ALA, SDA, ARA, and EPA) (Hixson et al., 2015), we expected to find a correlation in content between periphyton, emergent aquatic insects and riparian spiders. Indeed, we found a positive relationship in SDA content in periphyton, emergent insects and web spiders but not ground spiders, suggesting that SDA was exported from the aquatic system via emergent insects and then incorporated into web spiders. We also saw a positive relationship between ARA content in emergent aquatic insects and web spiders, implying that web spiders obtain their ARA at least partially from emergent insects. While ARA is a $\omega-6-$ PUFA associated with aquatic systems (Hixson et al., 2015), it was found in only small amounts in periphyton but higher amounts in aquatic invertebrates, other studies have found similar patterns (Ebm et al., 2020). The ARA source for aquatic invertebrates and ground spiders remains unclear.

We expected EPA content to be correlated among trophic levels, but no correlation was evident. Possible reasons for a 
A
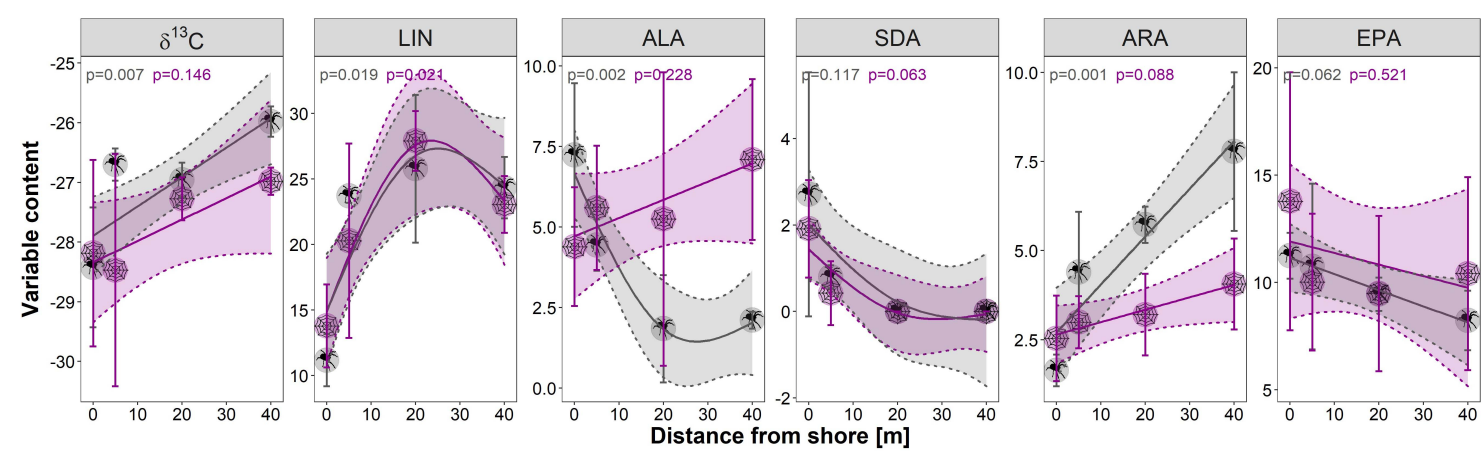

B

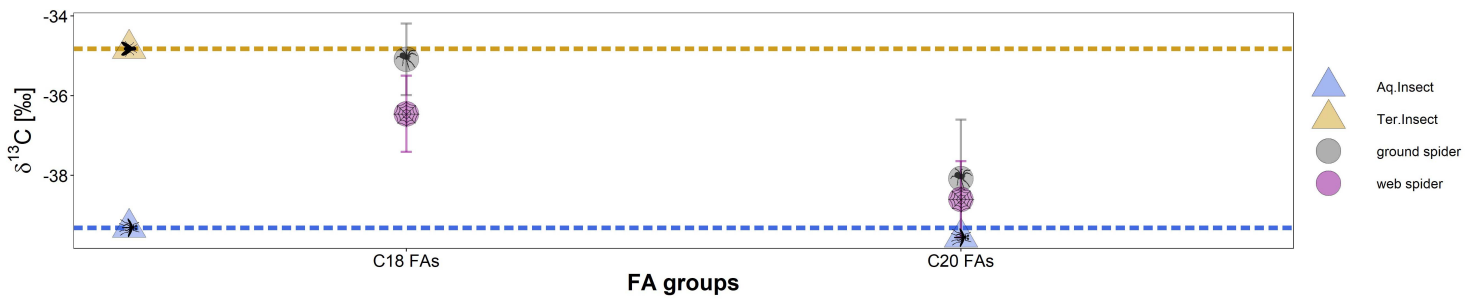

FIGURE 7 | (A) The relationship in $\delta^{13} \mathrm{C}$ and the different measured PUFAs (as \% of total fatty acids) with distance from stream shore at site N4 (Necker) in June (per distance $n=3$; except web spider $20 \mathrm{~m}, n=2)$ for web spiders and ground spiders; (B) Compound-specific carbon stable isotope ratios ( $\delta^{13} \mathrm{C}$ ) of combined C18 fatty acids and combined C20 fatty acids for web spiders $(n=3)$ and ground spiders $(n=3)$. Dashed lines represent average aquatic (blue) and terrestrial (orange) C18 fatty acids carbon isotope ratios. Symbols represent mean carbon isotope value for each group and error bars represent standard deviation.

lack of EPA association among trophic levels were (1) few strong site-specific differences in emergent insect EPA, (2) EPA accumulation in spider tissues, (3) the biomass of emergent insects and therefore PUFA export might be more important than actual PUFA content in single emergent insects, (4) internal metabolism, and (5) usage of an unknown terrestrial source (e.g., soil organisms). Here, we could exclude large quantities of internal EPA production or major terrestrial EPA sources (4 and 5) based on the distance gradient and compound-specific isotope analyses. The distance gradient showed a decrease in EPA content, albeit non-significant, with distance from shore. Further, in riparian spiders analyzed compound-specific, the $\delta^{13} \mathrm{C}$ ratio of C20 fatty acids, where EPA comprised the greatest proportion, was similar to that of aquatic sources. These results support the idea of an aquatic EPA origin because $\delta^{13} \mathrm{C}$ ratios of nutritionally valuable PUFAs have been shown to be relatively constant through trophic transfer with only minor fractionation (Burian et al., 2020). Results would have been clearer with a separation between single fatty acids, but this approach could not be used in this study due to limited technical resources. Even though we were not able to completely exclude internal conversion or terrestrial EPA sources, we still found strong evidence for a predominantly aquatic origin of EPA.

The correlation between ALA content in emergent aquatic insects and spiders was relatively weak, and thus did not confirm the aquatic origin of ALA. As terrestrial insects also contain ALA (Hixson et al., 2015), the ALA in spiders is likely a mixture from different sources. Lastly, we did not expect aquatic insects to be the main source of LIN for spiders, as LIN is present in large quantities in many terrestrial organisms, including the terrestrial
Diptera that we used as reference material. Indeed, we saw only a weak correlation between LIN content in aquatic Diptera and web spiders. LIN content especially in ground spiders increased with distance from shore, supporting the hypothesis that terrestrial insects are the main LIN source for riparian spiders. However, aquatic insects contain some LIN, so spiders that feed close to $100 \%$ on aquatic subsidies can still fulfill their LIN requirements. Lastly, our results indicate that season and spider type had strong influence on PUFA content and usage of aquatic subsidies in riparian spiders.

\section{Seasonal Patterns}

We expected to find the highest proportion of aquatic-derived resources and aquatic PUFAs, especially EPA, in spring when aquatic emergent insects are abundant and terrestrial insects are still relatively scarce (Nakano and Murakami, 2001; Uesugi and Murakami, 2007). While several isotope studies suggest riparian spiders use most aquatic-derived material in spring (Kato et al., 2004; Paetzold et al., 2005), we saw no significant change in $\delta^{13} \mathrm{C}$ ratio in spiders during the year. However, we observed a decrease in EPA from spring to summer to autumn, also indicating that aquatic subsidies are most widely used in spring. The proportion of aquatic vs. terrestrial material in spider diets using $\delta^{13} \mathrm{C}$ could be estimated only in spring, where we saw a significant difference in $\delta^{13} \mathrm{C}$ between aquatic and terrestrial insects. In summer and autumn, isotope signatures of Plecoptera and aquatic Diptera overlapped with the signal of terrestrial insects. The shift in the carbon isotope ratio of Plecoptera and aquatic Diptera reflected more terrestrial-derived resources being consumed in summer and autumn than spring. As food sources 


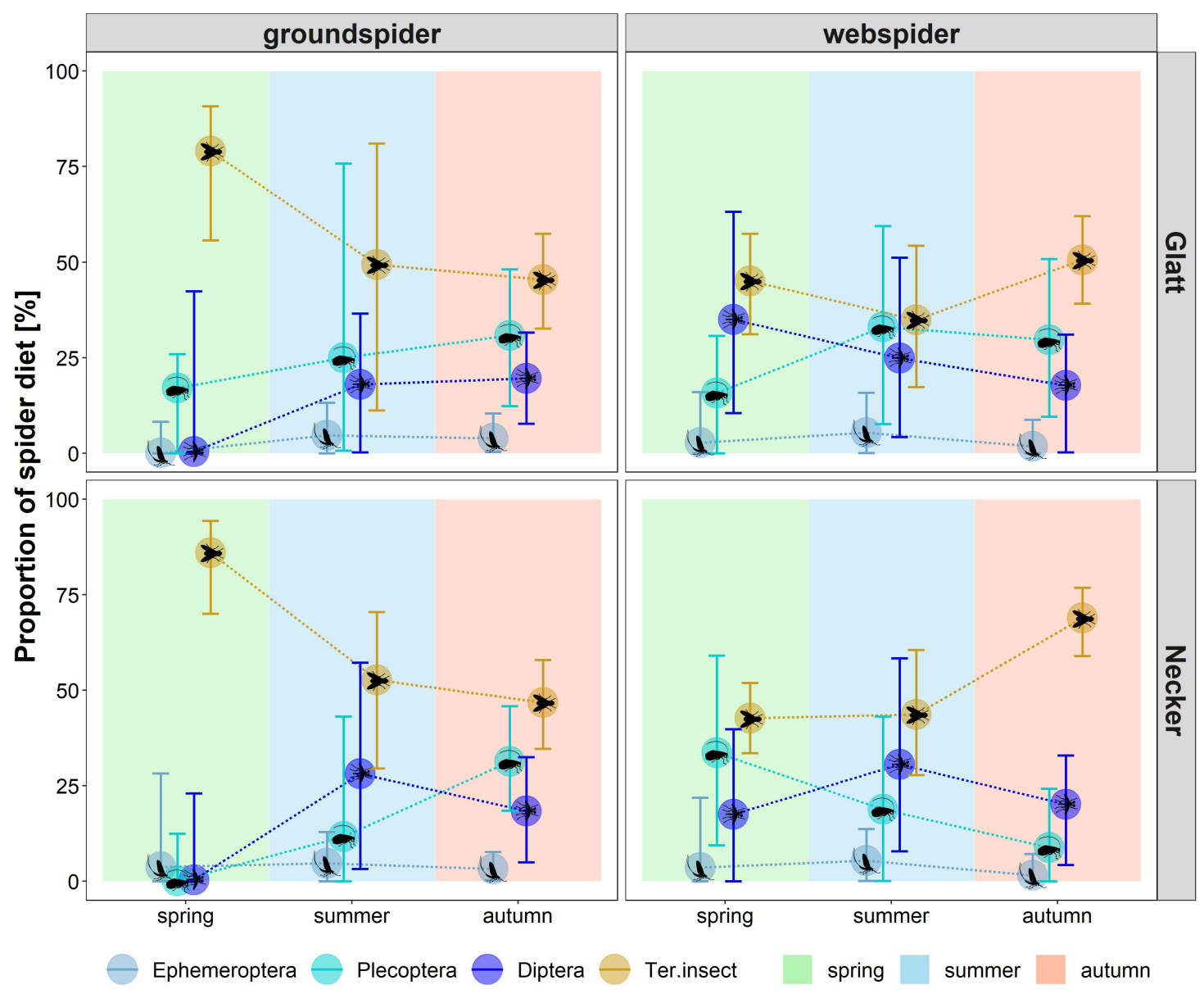

FIGURE 8 | Estimated dietary contribution of aquatic and terrestrial food sources derived from MixSIAR multi-source Bayesian model to diet of web spiders and ground spiders in spring, summer and autumn at the two different rivers. Dietary tracers included $\delta^{13} \mathrm{C}$, LIN, ALA, SDA, ARA and EPA for web spiders and $\delta^{13} \mathrm{C}$, LIN, ALA, SDA and EPA for ground spiders. Models were calculated separately for each season and spider type. Results are presented as median and 95\% credibility intervals.

could not be discriminated from each other, the usage of $\delta^{13} \mathrm{C}$ as method to reconstruct food sources was not possible. The $\delta^{13} \mathrm{C}$ ratio of spiders in summer and autumn showed that ingested carbon originated mostly from terrestrial sources, although likely in parts being cycled through the aquatic system and thereby the biomass being enriched in PUFAs.

The mixing model results, including PUFAs as dietary tracers, revealed higher amounts of aquatic-derived material in web spider diets in spring and summer than in autumn. For web spiders, PUFA profiles showed a changing trend from high EPA and SDA contents in spring to more LIN in autumn. Seasonal differences in ground spiders were less evident, although still containing highest EPA in spring. For ground spiders, a more consistent use of small amounts of aquatic subsidies across seasons seems likely. The mixing model including PUFAs showed a higher proportion of aquatic material in ground spider diet in summer and autumn than in spring and in the multivariate analysis ground spiders were most similar to aquatic insects in summer and autumn. Summarizing, aquatic subsidies provide an important dietary supplement to especially riparian web building spiders in early spring when other food sources are low in abundance, and might play a role in reproductive success as shown for other fauna such as birds (Twining et al., 2018). Importantly, we also found that EPA quantities in riparian spiders remained relatively high during summer and autumn, indicating an ongoing use of aquatic subsidies throughout the active period of the year.

\section{Comparison of Spider Types}

We saw a stronger aquatic-derived PUFA and stable isotope signature in web spiders than in ground spiders, especially in spring, as also reported in other studies using stable isotopes to estimate proportion of aquatic material in spider diet (e.g., Collier et al., 2002). The two spider types showed the most pronounced differences (PUFA profiles and $\delta^{13} \mathrm{C}$ ) in spring. For instance, stable isotope mixing model revealed that web spiders consumed on average approximately $40 \%$ and ground spiders $20 \%$ aquatic-derived carbon in spring. Other studies found up to $100 \%$ aquatic-derived material being consumed by spiders, especially web spiders (Sanzone et al., 2003). However, previous 
studies have found huge site-specific differences (Collier et al., 2002). As we only used terrestrial Diptera as a reference source, we likely underestimated the amount of aquatic-derived material consumed by spiders. We saw that spiders sampled $40-50 \mathrm{~m}$ from shore were less depleted in carbon than the terrestrial Diptera samples, indicating that other less depleted terrestrial carbon sources were available. However, although amount of aquatic material in the diet was likely underestimated, the relative difference of about $20 \%$ between the two spider types remained, suggesting that web spiders incorporated more aquatic-derived carbon than ground spiders in spring. Importantly, this finding indicates stationary web spiders, in contrast to roaming ground spiders, use this aquatic subsidy flux in spring when more aquatic than terrestrial insects are available. Ground spiders are more mobile and can find sufficient alternate prey in riparian areas, and appear to use fewer aquatic subsidies, when only considering isotope data.

However, ground spiders contained considerable amounts of EPA. The soil food web (nematodes/collembola) might be an alternative EPA source (Menzel et al., 2018), but the compoundspecific data indicated that the EPA found in ground spiders derived from aquatic sources. As EPA has been shown to be of physiological importance for ground spiders, especially the immune system (Fritz et al., 2017), it seems likely that riparian ground spiders, while accumulating the bulk of carbon from terrestrial sources, fulfill their EPA requirements by supplementing their diet with emergent aquatic insects. In fact, ground spiders might specifically accumulate/retain aquatic EPA such as other organisms that have been shown to have a higher transfer efficiency for PUFAs compared to bulk carbon (Gladyshev et al., 2011). In accordance to that, the mixing model including PUFAs estimated a higher proportion of aquatic material in both spider types' diets than the model using only $\delta^{13} \mathrm{C}$. While Ramberg et al. (2020) found a significantly higher EPA content in lycosid than tetragnathid spiders, we found no significant difference in EPA content between the spider types. In contrast, SDA content (and $\Sigma \omega 3 / \Sigma \omega 6$ ratio) was higher in web spiders than ground spiders in spring, albeit only significantly at the Necker. This result indicates that while ground spiders were generally low in SDA, web spiders incorporate this PUFA if available. Indeed, SDA content in web spiders was correlated with SDA content in emergent aquatic insects. A major difference between spider types that occurred consistently during all seasons was higher ARA content in ground spiders than web spiders (also see Ramberg et al., 2020). While the ARA content in web spiders was correlated with ARA content in emergent aquatic insects, ground spiders exhibited constantly higher values. It seems likely that certain spider groups (e.g., Lycosidae) have the metabolic machinery for metabolizing ARA or that they derive it from soil organisms; especially as the ARA content increased with distance from shore. This might also explain the differences between spider types, as ground-dwelling spiders have easier access to the soil food web and thus to potentially PUFA-rich prey, such as collembola. More research is needed regarding origin of ARA in riparian food webs. Apart from ARA, both spider types had similar PUFA profiles and $\delta^{13} \mathrm{C}$ ratios in summer and autumn, indicating similar diets, in contrast to spring.
We found multiple differences to what degree PUFA profiles of the spiders resemble those of aquatic insects. First, the time of year that PUFA profiles of spiders were most similar to aquatic insects differed between spider types. Web spiders were closely linked to emergent insects in spring and summer, while ground spiders showed most similarities in summer and autumn. Second, web spiders were most similar to aquatic Diptera, while ground spiders especially in autumn were most similar to Plecoptera. The reason might be that Plecoptera represent an important food source especially for ground-dwelling predators due to their emergence mode (Paetzold et al., 2005; Muehlbauer et al., 2020). Both spider types were distinct from terrestrial reference samples, mainly in their higher content in SDA and EPA, and ARA for ground spiders. As only terrestrial Diptera, being highly abundant, were measured as a reference for terrestrial material, a terrestrial separation in profiles from riparian spiders would likely be less clear if different terrestrial insects were included in the analysis. Here, we suggest additional terrestrial groups be included in future studies to better clarify profiles between aquatic and terrestrial sources.

Interestingly, spiders collected for the distance gradient directly at the shore $(0-2 \mathrm{~m})$ were more distinct from spiders of the same lifestyle/taxonomic group (genus level) further away from shore (10-50 m) than between lifestyles. Chari et al. (2020) also found a strong decrease of PUFAs associated with the aquatic system with distance from shore. This indicates that access to aquatic insects might be stronger driver of PUFA composition than lifestyle, as aquatic insect biomass steeply declines in the first 50 meters from shoreline (Muehlbauer et al., 2014).

\section{Fluvial Network Specific Differences}

The study was completed along a natural (Necker) and a heavily altered (Glatt) fluvial network. We expected to see lower proportion of aquatic diet (less depleted $\delta^{13} \mathrm{C}$ ratios) and less EPA in riparian spiders at the Glatt, because of a decoupling between the system due to the anthropogenic changes. Somewhat surprisingly, $\delta^{13} \mathrm{C}$ of spiders was on average more depleted at the Glatt than Necker, indicating higher proportion of aquatic material in the diet at the Glatt. There was no significant difference in EPA in spiders between systems. Other factors, like riparian vegetation structure, have been shown to influence PUFA profiles in riparian spiders (Ramberg et al., 2020), suggesting that site-specific differences along each system might be important as well. However, we saw higher SDA content in web spiders in spring in the more natural Necker. Further, SDA was found in aquatic insects and web spiders at the same sites SDA was present in periphyton, thus differences between systems occurred already at the base of the food web (i.e., primary producers). Different algae assemblages, involving taxa producing SDA in the Necker, might therefore explain the system differences. The nutrient status, higher in the Glatt than the Necker, likely caused differences in algal assemblages (Stelzer and Lamberti, 2001). Colombo et al. (2006) also found an association between cold temperatures and high SDA content in some types of algae, which might be important because of the higher water temperatures in the Glatt (mean annual temperature 2019: Glatt $10.7^{\circ} \mathrm{C}$ 
(Hydrograph station Oberbüren); Necker $9.2^{\circ} \mathrm{C}$ (Hydrograph station Mogelsberg)).

We also saw a more pronounced difference between the two spider types at the natural Necker in comparison to the anthropogenic Glatt. While we saw no general reduction of the food web connectivity between the two systems, we observed some specific differences especially a lower transfer of SDA and a lower $\Sigma \omega 3 / \Sigma \omega 6$ ratio in spring at the Glatt than Necker. Although the Glatt has elevated nutrient levels and a sediment deficit, its flow regime is mostly natural and many reaches along the river are not channelized, thus partially explaining the lower than expected differences in aquatic-derived subsidies between systems. Rivers showing even stronger regulatory alterations or pollution might show larger effects not only on spider populations (see Paetzold et al., 2011), but also in PUFA transfer.

\section{CONCLUSION}

Both web-building and ground-dwelling riparian spiders contained unusually high amounts of EPA for terrestrial consumers. While isotope data suggested that ground spiders derived only a small part of their carbon from aquatic sources, fatty acid analysis showed that both spider types used aquatic subsidies as an EPA source (dietary supplement). This was especially true for web spiders in spring. These results highlight that by including additional tracers, like PUFAs, in food web studies, we can track energy flow and exchange of important nutrients that might otherwise be overlooked. The difference in $\delta^{13} \mathrm{C}$ and PUFAs between spider lifestyles was pronounced in spring but small during the other seasons. Lastly, the difference between the anthropogenic and natural system was smaller than expected. We found mainly a higher SDA content and $\Sigma \omega 3 / \Sigma \omega 6$ ratio in web spiders in spring in the more natural system, but no difference in spider EPA content between systems. The high similarity in PUFA profiles, especially between aquatic Diptera and Plecoptera and riparian spiders, highlights the importance of emergent aquatic insects as vectors of PUFA transfer across ecosystem boundaries to riparian predators.

\section{REFERENCES}

Anderson, W. B., and Polis, G. A. (1998). Marine subsidies of island communities in the Gulf of California: evidence from stable carbon and nitrogen isotopes. Oikos 81, 75-80. doi: 10.2307/3546469

Bartels, P., Cucherousset, J., Steger, K., Eklöv, P., Tranvik, L. J., and Hillebrand, H. (2012). Reciprocal subsidies between freshwater and terrestrial ecosystems structure consumer resource dynamics. Ecology 93, 1173-1182. doi: 10.1890/ $11-1210.1$

Barton, K. (2020). MuMIn: Multi-Model Inference. $R$ package version 1.43.17.

Bates, D., Maechler, M., Bolker, B., and Walker, S. (2015). Fitting linear mixedeffects models using lme4. J. Stat. Softw. 67, 1-48.

Baxter, C. V., Fausch, K. D., and Carl Saunders, W. (2005). Tangled webs: reciprocal flows of invertebrate prey link streams and riparian zones. Freshw. Biol. 50, 201-220. doi: 10.1111/j.1365-2427.2004.01328.x

\section{DATA AVAILABILITY STATEMENT}

The raw data supporting the conclusions of this article will be made available by the authors, without undue reservation.

\section{AUTHOR CONTRIBUTIONS}

$\mathrm{CR}, \mathrm{CK}$, and DM-C did the conceptualization, writing - original draft preparation, and writing - review and editing. CK did the formal analysis and visualization. CK and CR did the project administration. CR did the funding acquisition. All authors have read and agreed to the published version of the manuscript.

\section{FUNDING}

Funding was provided by the Federal office of the environment (FOEN) as part of the research program "Hydraulic Engineering and Ecology." Any opinions, findings, conclusions or recommendations expressed in this material are those of the authors and do not necessarily reflect the views of the funders.

\section{ACKNOWLEDGMENTS}

We thank Noraen Barem, Sebastian Hartmaier, Christa Jolidon, Natascha Zinn, Benjamin Misteli, and Gabriele Consoli for assistance in the field and laboratory. Special thanks also to Petra Merkel and Carsten Schubert for their help with FA analysis. We further thank Serge Robert for the analysis of EA-IRMS and CSI samples. Thanks to Pierre Chanut for providing help with statistics and to all eco Ph.D. for inspiring discussions. Lastly, we would like to thank the reviewers for their thoughtful comments and efforts toward improving our manuscript.

\section{SUPPLEMENTARY MATERIAL}

The Supplementary Material for this article can be found online at: https://www.frontiersin.org/articles/10.3389/fevo.2021. 707570/full\#supplementary-material

Blomquist, G. J., Borgeson, C. E., and Vundla, M. (1991). Polyunsaturated fatty acids and eicosanoids in insects. Insect Biochem. 21, 99-106. doi: 10.1016/00201790(91)90069-q

Brenna, J. T., Salem, N. Jr., Sinclair, A. J., and Cunnane, S. C. (2009). $\alpha$-Linolenic acid supplementation and conversion to n-3 long-chain polyunsaturated fatty acids in humans. Prostaglandins Leukot. Essent. Fatty Acids 80, 85-91. doi: 10.1016/j.plefa.2009.01.004

Brett, M. T., Müller-Navarra, D. C., Ballantyne, A. P., Ravet, J. L., and Goldman, C. R. (2006). Daphnia fatty acid composition reflects that of their diet. Limnol. Oceanogr. 51, 2428-2437. doi: 10.4319/lo.2006.51.5.2428

Burdon, F. J., and Harding, J. S. (2008). The linkage between riparian predators and aquatic insects across a stream-resource spectrum. Freshw. Biol. 53, 330-346.

Burian, A., Nielsen, J. M., Hansen, T., Bermudez, R., and Winder, M. (2020). The potential of fatty acid isotopes to trace trophic transfer in aquatic food-webs. Philos. Trans. R. Soc. B 375:20190652. doi: 10.1098/rstb.2019.0652 
Callaway, J., Tennilä, T., and Pate, D. (1997). Occurrence of “omega-3" stearidonic acid (cis-6, 9, 12, 15-octadecatetraenoic acid) in hemp (Cannabis sativa L.) seed. J. Int. Hemp. Assoc. 3, 61-63.

Castro, L. F. C., Monroig, O., Leaver, M. J., Wilson, J., Cunha, I., and Tocher, D. R. (2012). Functional desaturase Fads1 $(\Delta 5)$ and Fads2 $(\Delta 6)$ orthologues evolved before the origin of jawed vertebrates. PLoS One 7:e31950. doi: 10.1371/journal. pone.0031950

Chapman, M., and Underwood, A. (1999). Ecological patterns in multivariate assemblages: information and interpretation of negative values in ANOSIM tests. Mar. Ecol. Prog. Ser. 180, 257-265. doi: 10.3354/meps180257

Chari, L., Richoux, N., Moyo, S., and Villet, M. (2020). Dietary fatty acids of spiders reveal spatial and temporal variations in aquatic-terrestrial linkages. Food Webs 24:e00152. doi: 10.1016/j.fooweb.2020.e00152

Collier, K. J., Bury, S., and Gibbs, M. (2002). A stable isotope study of linkages between stream and terrestrial food webs through spider predation. Freshw. Biol. 47, 1651-1659. doi: 10.1046/j.1365-2427.2002.00903.x

Colombo, M. L., Rise, P., Giavarini, F., De Angelis, L., Galli, C., and Bolis, C. (2006). Marine macroalgae as sources of polyunsaturated fatty acids. Plant Foods Hum. Nutr. 61, 64-69.

DeNiro, M. J., and Epstein, S. (1978). Influence of diet on the distribution of carbon isotopes in animals. Geochim. Cosmochim. Acta 42, 495-506. doi: 10.1016/ 0016-7037(78)90199-0

Ebm, N., Guo, F., Brett, M. T., Bunn, S. E., and Kainz, M. J. (2020). Polyunsaturated fatty acids in fish tissues more closely resemble algal than terrestrial diet sources. Hydrobiologia 848, 371-383. doi: 10.1007/s10750-020-04445-1

Filzmoser, P., and Gschwandtner, M. (2018). R-Package: 'mvoutlier'-Multivariate Outlier Detection Based on Robust Methods.

Fox, J., and Weisberg, S. (2019). An R Companion to Applied Regression, 3rd Edn. Thousand Oaks CA: Sage.

Fritz, K. A., Kirschman, L. J., McCay, S. D., Trushenski, J. T., Warne, R. W., and Whiles, M. R. (2017). Subsidies of essential nutrients from aquatic environments correlate with immune function in terrestrial consumers. Freshw. Sci. 36, 893-900. doi: 10.1086/694451

Fritz, K. A., Whiles, M. R., and Trushenski, J. T. (2019). Subsidies of longchain polyunsaturated fatty acids from aquatic to terrestrial environments via amphibian emergence. Freshw. Biol. 64, 832-842. doi: 10.1111/fwb.13266

Galloway, A. W., and Budge, S. M. (2020). The critical importance of experimentation in biomarker-based trophic ecology. R. Soc. 375:8.

Garrido, D., Kabeya, N., Hontoria, F., Navarro, J. C., Reis, D. B., Martín, M. V., et al. (2019). Methyl-end desaturases with $\Delta 12$ and $\omega 3$ regioselectivities enable the de novo PUFA biosynthesis in the cephalopod Octopus vulgaris. Biochim. Biophys. Acta (BBA) Mol. Cell Biol. Lipids 1864, 1134-1144. doi: 10.1016/j.bbalip.2019. 04.012

Gladyshev, M. I., Sushchik, N. N., Anishchenko, O. V., Makhutova, O. N., Kolmakov, V. I., Kalachova, G. S., et al. (2011). Efficiency of transfer of essential polyunsaturated fatty acids versus organic carbon from producers to consumers in a eutrophic reservoir. Oecologia 165, 521-531. doi: 10.1007/s00442-0101843-6

Gladyshev, M. I., Sushchik, N. N., and Makhutova, O. N. (2013). Production of EPA and DHA in aquatic ecosystems and their transfer to the land. Prostaglandins Other Lipid Mediat. 107, 117-126. doi: 10.1016/j.prostaglandins.2013.03.002

Guil-Guerrero, J. L. (2007). Stearidonic acid (18: 4n-3): metabolism, nutritional importance, medical uses and natural sources. Eur. J. Lipid Sci. Technol. 109, 1226-1236. doi: 10.1002/ejlt.200700207

Guo, F., Kainz, M. J., Sheldon, F., and Bunn, S. E. (2016). The importance of high-quality algal food sources in stream food webs-current status and future perspectives. Freshw. Biol. 61, 815-831. doi: 10.1111/fwb.12755

Harwood, J. L. (1996). Recent advances in the biosynthesis of plant fatty acids. Biochim. Biophys. Acta (BBA) Lipids Lipid Metab. 1301, 7-56. doi: 10.1016/ 0005-2760(95)00242-1

Hixson, S. M., Sharma, B., Kainz, M. J., Wacker, A., and Arts, M. T. (2015). Production, distribution, and abundance of long-chain omega-3 polyunsaturated fatty acids: a fundamental dichotomy between freshwater and terrestrial ecosystems. Environ. Rev. 23, 414-424. doi: 10.1139/er-2015-0029

Iverson, S. J., Field, C., Don Bowen, W., and Blanchard, W. (2004). Quantitative fatty acid signature analysis: a new method of estimating predator diets. Ecol. Monogr. 74, 211-235. doi: 10.1890/02-4105
Iwata, T. (2007). Linking stream habitats and spider distribution: spatial variations in trophic transfer across a forest-stream boundary. Ecol. Res. 22, 619-628. doi: 10.1007/s11284-006-0060-6

Iwata, T., Nakano, S., and Murakami, M. (2003). Stream meanders increase insectivorous bird abundance in riparian deciduous forests. Ecography 26, 325-337. doi: 10.1034/j.1600-0587.2003.03355.x

Jaschinski, S., Brepohl, D. C., and Sommer, U. (2011). Seasonal variation in carbon sources of mesograzers and small predators in an eelgrass community: stable isotope and fatty acid analyses. Mar. Ecol. Progr. Ser. 431, 69-82. doi: 10.3354/ meps09143

Kabeya, N., Fonseca, M. M., Ferrier, D. E., Navarro, J. C., Bay, L. K., Francis, D. S., et al. (2018). Genes for de novo biosynthesis of omega-3 polyunsaturated fatty acids are widespread in animals. Sci. Adv. 4:eaar6849. doi: 10.1126/sciadv. aar6849

Kabeya, N., Gür, İ, Oboh, A., Evjemo, J. O., Malzahn, A. M., Hontoria, F., et al. (2020). Unique fatty acid desaturase capacities uncovered in Hediste diversicolor illustrate the roles of aquatic invertebrates in trophic upgrading. Philos. Trans. R. Soc. B 375:20190654. doi: 10.1098/rstb.2019.0654

Kato, C., Iwata, T., Nakano, S., and Kishi, D. (2003). Dynamics of aquatic insect flux affects distribution of riparian web-building spiders. Oikos 103, 113-120. doi: 10.1034/j.1600-0706.2003.12477.x

Kato, C., Iwata, T., and Wada, E. (2004). Prey use by web-building spiders: stable isotope analyses of trophic flow at a forest-stream ecotone. Ecol. Res. 19, 633-643. doi: 10.1111/j.1440-1703.2004.00678.x

Laeser, S. R., Baxter, C. V., and Fausch, K. D. (2005). Riparian vegetation loss, stream channelization, and web-weaving spiders in northern Japan. Ecol. Res. 20, 646-651. doi: 10.1007/s11284-005-0084-3

Lam, M. M.-Y., Martin-Creuzburg, D., Rothhaupt, K.-O., Safi, K., Yohannes, E., and Salvarina, I. (2013). Tracking diet preferences of bats using stable isotope and fatty acid signatures of faeces. PLoS One 8:e83452. doi: 10.1371/journal. pone. 0083452

Larsen, S., Muehlbauer, J. D., and Marti, E. (2016). Resource subsidies between stream and terrestrial ecosystems under global change. Glob. Chang. Biol. 22, 2489-2504. doi: 10.1111/gcb.13182

Lenth, R. V. (2021). emmeans: Estimated Marginal Means, aka Least-Squares Means. R package version 1.5.4.

Martin-Creuzburg, D., Kowarik, C., and Straile, D. (2017). Cross-ecosystem fluxes: export of polyunsaturated fatty acids from aquatic to terrestrial ecosystems via emerging insects. Sci. Total Environ. 577, 174-182. doi: 10.1016/j.scitotenv. 2016.10.156

Martin-Creuzburg, D., Wacker, A., and Basena, T. (2010). Interactions between limiting nutrients: consequences for somatic and population growth of Daphnia magna. Limnol. Oceanogr. 55, 2597-2607. doi: 10.4319/lo.2010.55.6.2597

Menzel, R., Geweiler, D., Sass, A., Simsek, D., and Ruess, L. (2018). Nematodes as important source for omega-3 long-chain fatty acids in the soil food web and the impact in nutrition for higher trophic levels. Front. Ecol. Evol. 6:96. doi: 10.3389/fevo.2018.00096

Moyo, S., Chari, L. D., Villet, M. H., and Richoux, N. B. (2017). Decoupled reciprocal subsidies of biomass and fatty acids in fluxes of invertebrates between a temperate river and the adjacent land. Aquat. Sci. 79, 689-703. doi: 10.1007/ s00027-017-0529-0

Muehlbauer, J. D., Collins, S. F., Doyle, M. W., and Tockner, K. (2014). How wide is a stream? Spatial extent of the potential "stream signature" in terrestrial food webs using meta-analysis. Ecology 95, 44-55. doi: 10.1890/121628.1

Muehlbauer, J. D., Larsen, S., Jonsson, M., and Emilson, E. J. S. (2020). "Variables affecting resource subsidies from streams and rivers to land and their susceptibility to global change stressors," in Contaminants and Ecological Subsidies: The Land-Water Interface, eds J. M. Kraus, D. M. Walters, and M. A. Mills (Cham: Springer International Publishing), 129-155. doi: 10.1007/978-3030-49480-3_7

Müller-Navarra, D. C., Brett, M. T., Liston, A. M., and Goldman, C. R. (2000). A highly unsaturated fatty acid predicts carbon transfer between primary producers and consumers. Nature 403:74. doi: 10.1038/47469

Nakagawa, S., and Cuthill, I. C. (2007). Effect size, confidence interval and statistical significance: a practical guide for biologists. Biol. Rev. 82, 591-605. doi: 10. 1111/j.1469-185x.2007.00027.x 
Nakagawa, S., and Schielzeth, H. (2013). A general and simple method for obtaining R2 from generalized linear mixed-effects models. Methods Ecol. Evol. 4, 133-142. doi: 10.1111/j.2041-210x.2012.00261.x

Nakano, S., and Murakami, M. (2001). Reciprocal subsidies: dynamic interdependence between terrestrial and aquatic food webs. Proc. Natl. Acad. Sci. 98, 166-170. doi: 10.1073/pnas.98.1.166

Nyffeler, M., Sterling, W., and Dean, D. (1994). How spiders make a living. Environ. Entomol. 23, 1357-1367. doi: 10.1093/ee/23.6.1357

Oelbermann, K., and Scheu, S. (2002). Stable isotope enrichment ( $\delta 15 \mathrm{~N}$ and $\delta$ $13 \mathrm{C}$ ) in a generalist predator (Pardosa lugubris, Araneae: Lycosidae): effects of prey quality. Oecologia 130, 337-344. doi: 10.1007/s004420100813

Oksanen, J., Blanchet, F. G., Friendly, M., Kindt, R., Legendre, P., McGlinn, D., et al. (2019). vegan: Community Ecology Package. R package version 2.5-6.

Paetzold, A., Schubert, C. J., and Tockner, K. (2005). Aquatic terrestrial linkages along a braided-river: riparian arthropods feeding on aquatic insects. Ecosystems 8, 748-759. doi: 10.1007/s10021-005-0004-y

Paetzold, A., Smith, M., Warren, P. H., and Maltby, L. (2011). Environmental impact propagated by cross-system subsidy: chronic stream pollution controls riparian spider populations. Ecology 92, 1711-1716. doi: 10.1890/10-2184.1

Paetzold, A., Yoshimura, C., and Tockner, K. (2008). Riparian arthropod responses to flow regulation and river channelization. J. Appl. Ecol. 45, 894-903. doi: 10.1111/j.1365-2664.2008.01463.x

Pawlosky, R., Denkins, Y., Ward, G., and Salem, N. Jr. (1997). Retinal and brain accretion of long-chain polyunsaturated fatty acids in developing felines: the effects of corn oil-based maternal diets. Am. J. Clin. Nutr. 65, 465-472. doi: 10.1093/ajcn/65.2.465

Popova, O. N., Haritonov, A. Y., Sushchik, N. N., Makhutova, O. N., Kalachova, G. S., Kolmakova, A. A., et al. (2017). Export of aquatic productivity, including highly unsaturated fatty acids, to terrestrial ecosystems via Odonata. Sci. Total Environ. 581, 40-48. doi: 10.1016/j.scitotenv.2017.01.017

R Core Team (2019). R: A Language and Environment for Statistical Computing. Vienna: R Foundation for Statistical Computing.

Ramberg, E., Burdon, F. J., Sargac, J., Kupilas, B., Rîşnoveanu, G., Lau, D. C., et al. (2020). The structure of riparian vegetation in agricultural landscapes influences spider communities and aquatic-terrestrial linkages. Water 12:2855. doi: $10.3390 /$ w12102855

Richardson, J. S., Zhang, Y., and Marczak, L. B. (2010). Resource subsidies across the land-freshwater interface and responses in recipient communities. River Res. Appl. 26, 55-66. doi: 10.1002/rra.1283

Rounick, J., and Winterbourn, M. (1986). Stable carbon isotopes and carbon flow in ecosystems. BioScience 36, 171-177. doi: 10.2307/1310304

Sabo, J., and Power, M. (2002). River-watershed exchange: effects of riverine subsidies on riparian lizards and their terrestrial prey. Ecology 83, 1860-1869. doi: $10.2307 / 3071770$

Sanzone, D., Meyer, J., Martí, E., Gardiner, E., Tank, J., and Grimm, N. (2003). Carbon and nitrogen transfer from a desert stream to riparian predators. Oecologia 134, 238-250. doi: 10.1007/s00442-002-1113-3

Sayanova, O. V., and Napier, J. A. (2004). Eicosapentaenoic acid: biosynthetic routes and the potential for synthesis in transgenic plants. Phytochemistry 65, 147-158. doi: 10.1016/j.phytochem.2003.10.017

Schlotz, N., Roulin, A., Ebert, D., and Martin-Creuzburg, D. (2016). Combined effects of dietary polyunsaturated fatty acids and parasite exposure on eicosanoid-related gene expression in an invertebrate model. Comp. Biochem. Physiol. A Mol. Integr. Physiol. 201, 115-123. doi: 10.1016/j.cbpa.2016.07.008

Sokal, R. R., and Rohlf, J. F. (1995). Biometry. San Francisco, CA: W.H. Freeman.
Stanley, D. W. (2014). Eicosanoids in Invertebrate Signal Transduction Systems. Princeton, NJ: Princeton University Press.

Stelzer, R. S., and Lamberti, G. A. (2001). Effects of N: P ratio and total nutrient concentration on stream periphyton community structure, biomass, and elemental composition. Limnol. Oceanogr. 46, 356-367. doi: 10.4319/lo. 2001.46.2.0356

Stillwell, W., and Wassall, S. R. (2003). Docosahexaenoic acid: membrane properties of a unique fatty acid. Chem. Phys. Lipids 126, 1-27. doi: 10.1016/ s0009-3084(03)00101-4

Stock, B. C., Jackson, A. L., Ward, E. J., Parnell, A. C., Phillips, D. L., and Semmens, B. X. (2018). Analyzing mixing systems using a new generation of Bayesian tracer mixing models. PeerJ 6:e5096. doi: 10.7717/peerj.5096

Torres-Ruiz, M., Wehr, J. D., and Perrone, A. A. (2007). Trophic relations in a stream food web: importance of fatty acids for macroinvertebrate consumers. J. North Am. Benthol. Soc. 26, 509-522. doi: 10.1899/06-070.1

Torres-Ruiz, M., Wehr, J. D., and Perrone, A. A. (2010). Are net-spinning caddisflies what they eat? An investigation using controlled diets and fatty acids. J. North Am. Benthol. Soc. 29, 803-813. doi: 10.1899/09-162.1

Twining, C. W., Bernhardt, J., Derry, A., Hudson, C., Ishikawa, A., Kabeya, N., et al. (2020a). The evolutionary ecology of fatty-acid variation: implications for consumer adaptation and diversification. Authorea Preprints [Preprint].

Twining, C. W., Brenna, J. T., Hairston, N. G., and Flecker, A. S. (2016a). Highly unsaturated fatty acids in nature: what we know and what we need to learn. Oikos 125, 749-760. doi: 10.1111/oik.02910

Twining, C. W., Brenna, J. T., Lawrence, P., Shipley, J. R., Tollefson, T. N., and Winkler, D. W. (2016b). Omega-3 long-chain polyunsaturated fatty acids support aerial insectivore performance more than food quantity. Proc. Natl. Acad. Sci. U.S.A. 113, 10920-10925. doi: 10.1073/pnas.1603998113

Twining, C. W., Shipley, J. R., and Winkler, D. W. (2018). Aquatic insects rich in omega-3 fatty acids drive breeding success in a widespread bird. Ecol. Lett. 21, 1812-1820. doi: 10.1111/ele.13156

Twining, C. W., Taipale, S. J., Ruess, L., Bec, A., Martin-Creuzburg, D., and Kainz, M. J. (2020b). Stable isotopes of fatty acids: current and future perspectives for advancing trophic ecology. Philos. Trans. R. Soc. B 375:20190641. doi: 10.1098/rstb.2019.0641

Uesugi, A., and Murakami, M. (2007). Do seasonally fluctuating aquatic subsidies influence the distribution pattern of birds between riparian and upland forests? Ecol. Res. 22, 274-281. doi: 10.1007/s11284-006-0028-6

Uttaro, A. D. (2006). Biosynthesis of polyunsaturated fatty acids in lower eukaryotes. IUBMB Life 58, 563-571. doi: 10.1080/15216540600920899

Wise, D. (1993). Spiders in Ecological Webs. New York, NY: Cambridge University Press.

Wood, S. N. (2017). Generalized Additive Models: An Introduction with R. Boca Raton, FL: CRC press.

Conflict of Interest: The authors declare that the research was conducted in the absence of any commercial or financial relationships that could be construed as a potential conflict of interest.

Copyright (c) 2021 Kowarik, Martin-Creuzburg and Robinson. This is an open-access article distributed under the terms of the Creative Commons Attribution License (CC BY). The use, distribution or reproduction in other forums is permitted, provided the original author(s) and the copyright owner(s) are credited and that the original publication in this journal is cited, in accordance with accepted academic practice. No use, distribution or reproduction is permitted which does not comply with these terms. 